This manuscript is currently under peer-review. The content is subject to potential

revision. Please cite final published version.

\title{
Climate anxiety, pro-environmental action and wellbeing: antecedents and outcomes of negative emotional responses to climate change in 28 countries
}

Charles Ogunbode ${ }^{1 *}$, Rouven Doran², Daniel Hanss ${ }^{3}$, Maria Ojala ${ }^{4}$, Katariina Salmela-Aro ${ }^{5}$, Karlijn L. van den Broek ${ }^{6,7}$, Navjot Bhullar ${ }^{8}$, Sibele D. Aquino ${ }^{9}$, Tiago Marot $^{9}$, Julie Aitken Schermer ${ }^{10}$, Anna Wlodarczyk ${ }^{11}$, Su Lu ${ }^{12}$, Feng Jiang ${ }^{13}$, Daniela Acquadro Maran ${ }^{14}$, Radha Yadav $^{15}$, Rahkman Ardi ${ }^{16}$, Razieh Chegeni' ${ }^{2}$ Elahe Ghanbarian ${ }^{17}$, Somayeh Zand ${ }^{18}$, Reza Najafi ${ }^{19}$, Joonha Park ${ }^{20}$, Takashi Tsubakita ${ }^{20}$, Chee-Seng Tan ${ }^{21}$, JohnBosco Chika Chukwuorji $^{22}$, Kehinde Ojewumi ${ }^{23}$, Hajra Tahir ${ }^{2}$, Mai Albzour ${ }^{24}$, Marc Eric S. Reyes ${ }^{25}$, Samuel Lins $^{26}$, Violeta Enea ${ }^{27}$, Tatiana Volkodav ${ }^{28}$, Tomas Sollar ${ }^{29}$, Ginés Navarro-Carrillo ${ }^{30}$, Jorge Torres-Marín ${ }^{31}$, Winfred Mbungu ${ }^{32}$, Arin H. Ayanian ${ }^{33}$, Jihane Ghorayeb ${ }^{34}$, Charles Onyutha ${ }^{35}$, Michael J. Lomas ${ }^{36}$.

\section{Affiliations:}

${ }^{1}$ School of Psychology, University of Nottingham, UK

${ }^{2}$ Department of Psychosocial Science, Faculty of Psychology, University of Bergen, Norway

${ }^{3}$ Department of Social Sciences, Darmstadt University of Applied Sciences, Germany

${ }^{4}$ School of Law, Psychology and Social Work, Örebro University, Sweden

${ }^{5}$ Department of Educational Sciences, University of Helsinki, Finland

${ }^{6}$ Copernicus Institute of Sustainable Development, Utrecht University, Netherlands

${ }^{7}$ Research Centre for Environmental Economics, Heidelberg University, Germany

${ }^{8}$ School of Psychology, University of New England, New South Wales, Australia

${ }^{9}$ Psychology Department, Pontifical Catholic University of Rio de Janeiro, Brazil

${ }^{10}$ Department of Management and Organisational Studies, Faculty of Social Science, University of

Western Ontario, Canada

${ }^{11}$ Escuela de Psicología, Facultad de Humanidades, Universidad Católica del Norte, Chile

${ }^{12}$ School of Applied Social Sciences, De Montfort University, UK

${ }^{13}$ Department of Human Resources and Organisational Behaviour, University of Greenwich, UK

${ }^{14}$ Department of Psychology, University of Torino, Italy

${ }^{15}$ School of Business and Management, Christ University, India

${ }^{16}$ Departement of Psychology, Universitas Airlangga, Indonesia

${ }^{17}$ Department of Educational Psychology and Counselling, University of Tehran, Iran

${ }^{18}$ Department of Psychology, University of Milano-Bicocca, Italy

${ }^{19}$ Department of General Psychology, University of Padova, Italy

${ }^{20}$ Nagoya University of Commerce and Business, Japan

${ }^{21}$ Department of Psychology and Counselling, Faculty of Arts and Social Science, Universiti Tunku Abdul Rahman, Malaysia

${ }^{22}$ Department of Psychology, University of Nigeria, Nigeria

${ }^{23}$ Department of Psychology, Obafemi Awolowo University, Nigeria

${ }^{24}$ Department of Social and Behavioural Science, Birzeit University, Palestine

${ }^{25}$ College of Science, University of Santo Tomas, Philippines

${ }^{26}$ Faculty of Psychology and Education Sciences, University of Porto, Portugal

${ }^{27}$ Department of Psychology, Alexandru loan Cuza University of lasi, Romania

${ }^{28}$ Faculty of Pedagogy, Psychology and Communicology, Kuban State University, Russia

${ }^{29}$ Department of Psychological Sciences, Faculty of Social Sciences and Healthcare, Constantine the Philosopher University in Nitra, Slovakia

${ }^{30}$ Department of Psychology, University of Jaén, Spain

${ }^{31}$ Department of Research Methods in Behavioural Sciences, University of Granada, Spain

${ }^{32}$ Department of Civil and Water Resources Engineering, School of Engineering and Technology,

Sokoine University of Agriculture, Tanzania 
${ }^{33}$ Institute for Interdisciplinary Research on Conflict and Violence, Bielefeld University, Germany ${ }^{34}$ Department of Psychology, Zayed University, Dubai, United Arab Emirates

${ }^{35}$ Department of Civil and Environmental Engineering, Kyambogo University, Uganda

${ }^{36}$ School of Health and Society, University of Salford, UK

${ }^{*}$ Corresponding author:

Charles Ogunbode

School of Psychology

University of Nottingham

B65 Psychology

University Park, Nottingham

United Kingdom

NG7 2RD

Email: charles.ogunbode@nottingham.ac.uk

Phone: (44) 01157486691 
Climate anxiety, pro-environmental action and wellbeing: antecedents and outcomes of negative emotional responses to climate change in 28 countries.

\begin{abstract}
This study explored the antecedents and outcomes of negative emotional responses to climate change across a diverse range of national contexts. We analysed cross-sectional data gathered in 28 countries $(N=10,963)$. Our results show that negative emotional responses to climate change are positively related to the amount of attention people pay to climate change information, rates of exposure to information about climate change impacts, and perceived social expectations about emotional responding to climate change. Negative climate-related emotions were also positively linked to pro-environmental behaviours and inversely related to mental wellbeing. Notably, while negative climate-related emotions had a significant inverse association with mental wellbeing in all 28 countries, they only significantly predicted proenvironmental behaviour (46\%) and environmental activism (25\%) in a minority of countries. Our findings highlight contextual boundaries to engagement in environmental action as an antidote to climate anxiety, and the broad international significance of negative climate-related emotions as a plausible threat to wellbeing.
\end{abstract}

Keywords: Climate change anxiety; Climate change; Wellbeing; Pro-environmental behaviour; Climate activism; Emotions

\title{
1. Introduction
}

Climate change is recognised as a major threat by most people around the world. In 2020, more than half of respondents (55\%) in a UK national survey reported that they perceive climate change to be a bigger threat to the world than COVID-19 (Evensen et al., 2021). Similarly, a 2021 survey of 76,328 Facebook users across 31 countries showed that most respondents were "somewhat" or "very" worried about climate change (Leiserowitz et al., 2021). As the acute and long-term effects of climate change become a lived experience for a growing proportion of the world's population, there also appears to be a corresponding rise in the number of people experiencing psychological distress in relation to the environment and climate crisis (Ojala et al., 2021; Pihkala, 2020). Commonly termed "eco-anxiety" or "climate anxiety", the experience of environment-related distress encompasses negative emotions like fear, worry, anger, guilt, shame, hopelessness and despair (Marks et al., 2021; Ojala et al., 2021). It has been noted that anxiety has simply emerged as a concept used by researchers to represent a wide range of negative emotions people have regarding climate change (Clayton, 2020). 
To date, mainstream discourse and research regarding emotional responses to climate change have predominantly focused on the experiences and perspectives of a white and Western demographic (Ray, 2021). Yet, the existential threat posed by climate change is by no means limited to the Global North. In a recent international poll of young adults, most respondents in four countries of the Global South: Brazil (86\%), India (80\%), Nigeria (70\%), and the Philippines (92\%), reported feeling frightened about the future because of climate change (Marks et al., 2021). Another study showed that climate anxiety is associated with poor mental health among a sample of Filipino young adults (Reyes et al., 2021). The current study builds on emerging efforts to diversify climate-related emotions research. We explored the antecedents of negative climate-related emotions, as well as compared how negative emotional responses to climate change relate to pro-environmental action and mental wellbeing in 28 countries.

\subsection{Antecedents of negative climate-related emotions}

Based on existing research, we focused on three main factors as plausible antecedents of negative emotional responses to climate change - media exposure, social norms, and personal experience.

\subsubsection{Media effects}

Exposure to media coverage of natural disasters has been associated with intensified negative emotions (Houston, First, et al., 2018; Pfefferbaum et al., 2014). This association is prominent for post-traumatic stress responses, but other reactions like distress and anxiety have also been reported (Pfefferbaum et al., 2014). Exposure to disaster media can lead to strong negative emotional reactions by feeding extremely negative appraisals of the portrayed issues/events as posing a risk to oneself or important others (Ehlers \& Clark, 2000; Houston, Spialek, et al., 2018), or by cultivating a generalised perception of the world as unsafe (Gerbner et al., 2002).

Scholars have speculated that rising rates of exposure to information about environmental problems via the media may be related to increased negative eco-emotions and poor wellbeing (Stokols et al., 2009), but there is limited empirical support for this speculation in the context of negative climate-related emotions. A study conducted in India showed no significant relationship between media use and climate change attitudes (Thaker et al., 2017). Another study observed no significant effect of information exposure on climate change perceptions among an indigenous community in Bolivia (Fernández-Llamazares et al., 2015). Yet, exposure to the 2018 IPCC report on $1.5^{\circ} \mathrm{C}$ global warming was found to be associated with heightened climate change concern in Norway, and most respondents in the study encountered the report through the media (Ogunbode et al., 2020a). Research has also shown 
a positive link between media exposure and climate change concern in Japan (Sampei \& Aoyagi-Usui, 2009). Therefore, we hypothesized that:

H1: Exposure to climate change-related media is positively associated with negative climate-related emotions

Over and above the mere rate of exposure to climate-related media, attention to such information may also significantly predict the intensity of negative emotional responses to climate change. Media exposure and media attention are conceptually distinct and have unique relationships with specific media effects (Drew \& Weaver, 2016). While media exposure refers to the quantity of media viewed or heard regarding a specific topic, media attention refers to the inclination to channel cognitive resources into processing the messages conveyed via these media (Lee \& Cho, 2019). Some studies suggest that attention to media may be a better predictor of media effects than media exposure alone. For example, attention to news about social risks, like crime, has been shown to be more strongly predictive of risk judgements than self-reported media use (Slater \& Rasinski, 2005). Similarly, attention to sustainability media has been shown to predict pro-environmental behaviour and green consumerism more strongly than exposure to sustainability media (Lee \& Cho, 2019). Hence, we hypothesized that:

H2: Attention to climate change-related media is positively associated with negative climate-related emotions

Negative emotional responses to climate change are also likely to be influenced by the content of the information to which individuals are exposed, especially whether the information mainly relates to climate change causes, consequences (impacts) or solutions. Previous research has linked knowledge of the causes and consequences of climate change to increased climate change concern (J. Shi et al., 2016). Therefore, we expected that exposure to information about the causes or impacts of climate change will be positively related to negative climaterelated emotions. In contrast, exposure to information that focuses on climate change solutions is likely to reduce negative climate-related emotions. For example, previous research has found that people report reduced levels of distress when presented with optimistic information about progress in reducing global carbon emissions (Hornsey \& Fielding, 2016). Thus, we hypothesized that:

H3a: Exposure to information about climate change causes is positively associated with negative climate-related emotions

H3b: Exposure to information about climate change impacts is positively associated with negative climate-related emotions 
H3c: Exposure to information about climate change solutions is inversely related to negative climate-related emotions

\subsubsection{Social norms}

Social life is characterised by shared patterns of thought, behaviour and feeling, otherwise known as social norms (Hogg \& Reid, 2006). Drawing from the focus theory of normative conduct (Cialdini et al., 1991), there are two categories of social norms. The first is descriptive norms, which refers to a person's perception of what the majority of people do in a given situation. The second is injunctive norms, which refers to perceptions of what behaviours important social referents (e.g., family, friends, colleagues or neighbours) approve or disapprove of in specific situations. People are more likely to enact adaptive behavioural responses to climate change when they perceive social norms to be supportive of such behaviour (van Valkengoed \& Steg, 2019). Social norms also seem to matter for climate change perceptions and emotions more broadly. For example, people report a greater sense of threat from climate change when they believe that important social referents are engaging in climate action or when they feel social pressure to personally act on climate change (van der Linden, 2014). Similarly, people are more likely to express worry about climate change when close others, such as friends and family members, are perceived to also care about climate change (Goldberg et al., 2020). Consequently, we anticipated that:

H4a: Descriptive norms supporting expression of negative emotional responses to climate change are positively associated with individual's levels of negative climaterelated emotions.

H4b. Injunctive norms supporting expression of negative emotional responses to climate change are positively associated with individuals' levels of negative climaterelated emotions.

\subsubsection{Personal experience}

People often draw on their personal experiences with extreme weather to make inferences about the reality of climate change (McDonald et al., 2015). Experience of extreme events like flooding and hurricanes can heighten climate change concern by making climate change feel more concrete and immediate (Bergquist et al., 2019; Myers et al., 2013; Spence et al., 2011). Through a process of experiential learning, negative emotions triggered by extreme weather experiences can become intuitively associated with climate change and subsequently feed into the way people perceive the climate risks (Marx et al., 2007). Some studies suggest that extreme weather experiences may have a transient effect on climate change concern (Konisky et al., 2016), or no effect at all (Whitmarsh, 2008). Others indicate that individuals' values, pre- 
existing beliefs and subjective attribution of their experiences often moderate how extreme weather experiences shape responses to climate change (Bruine de Bruin et al., 2014; Ogunbode et al., 2017, 2019, 2020b). Like climate-related emotions, much of the research on extreme weather experiences and climate change engagement has focused on a narrow range of cultural contexts. In the current study, we explored how personal experiences of extreme weather relate to negative climate-related emotions. Specifically, we hypothesized that:

H5: Extreme weather experiences are positively associated with negative climate-related emotions

1.2. Pro-environmental behaviour, environmental activism, and mental wellbeing

Negative emotional responses to perceived threats often trigger information-seeking tendencies and can encourage constructive coping by focusing people's attention on information about potential solutions (Hmielowski et al., 2019). Indeed, worry and anxiety about climate change have been linked with climate change policy support and proenvironmental behaviour (Bouman et al., 2020; Stanley et al., 2021; Wullenkord et al., 2021). However, it is important to distinguish between different categories of pro-environmental behaviours as different combinations of causal factors may be associated with each category. According to Stern (2000), environmentally-significant behaviours can be divided into four main categories: environmental activism (e.g., involvement in environmental protests or demonstrations), non-activist behaviours in the public sphere (e.g., petitioning on environmental issues), private-sphere behaviours (e.g., recycling and green consumerism) and behaviours in organisations (e.g., attendance to environmental criteria in decision-making and organisational practices). In the current study, we assessed how negative climate-related emotions relate to private-sphere pro-environmental behaviours (henceforth termed proenvironmental behaviour) and engagement in environmental activism.

Importantly, negative emotions do not always lead to constructive coping, especially when the scale of the perceived threat exceeds available coping resources (Ojala et al., 2021). A growing number of studies show that climate anxiety is significantly related to depressive symptoms, poor mental health, and lowered psychological wellbeing (Ogunbode et al., 2021; Reyes et al., 2021; Stanley et al., 2021; Wullenkord et al., 2021). Alongside direct experiences of physical, social, and economic impacts from extreme weather events and gradual environmental changes, negative emotions associated with heightened awareness of the climate crisis could also be a pathway by which climate change impacts mental wellbeing (Clayton, 2020; Gibson et al., 2020). The nature of the relationship between climate anxiety and wellbeing is complicated. Nonetheless, scholars have argued that climate anxiety is a 
rational, rather than pathological, emotional response that generally leads to constructive attitudinal and behavioural outcomes (Clayton \& Karazsia, 2020; Pihkala, 2020). In line with this, we anticipated that:

H6a: Negative climate-related emotions are positively associated with proenvironmental behaviour

H6b: Negative climate-related emotions are positively associated with engagement in environmental activism

H7: Negative climate-related emotions are inversely related to mental wellbeing.

\section{Method}

\subsection{Participants and procedure}

We gathered data in 28 countries $\left(N=10,963 ; M_{\text {age }}=23.3\right.$ years, $S D_{\text {age }}=7.1$ years, Females $=63.2 \%$, Males $=33.2 \%$ ) using a structured questionnaire. Data collection was conducted in 25 of the countries in autumn 2019 but continued in three countries (India, Palestine, and the United Arab Emirates) until late summer 2020 due to interruption by the onset of the COVID19 pandemic. The questionnaire was administered in paper-and-pencil format or online, depending on what was most practical in each country. In all countries, we recruited respondents from university research participant pools or through opportunity sampling of university students. Participation in the study was strictly by voluntary consent. Rewards (e.g., course credit, entry into a raffle) were offered to participants in a few countries in accordance with local conventions. The final sample size was circumscribed by the number of accessible voluntary participants in each country.

The questionnaire was originally prepared in English and subsequently translated to other relevant languages using a system of translation-back-translation involving at least one bilingual speaker. Ethical approval for the study was granted by the [redacted for anonymous review] University Health and Life Sciences Faculty Research Ethics Committee (Ref: 3434), with supplementary approval also obtained in countries where this was required. A countrywise demographic profile of the sample is provided as supplementary data (Supplementary Table 1).

\subsection{Measures}

\subsubsection{Negative climate-related emotions}

We measured negative climate-related emotions with a 7-item scale based on the state anxiety component of the State-Trait Anxiety Inventory (Spielberger, 1983). Participants were instructed to collect their thoughts and focus on their feelings regarding climate change. Subsequently, they were directed to indicate the degree to which they felt calm, tense, relaxed, 
anxious, peaceful, worried or terrified about climate change at that moment in time. Ratings for each emotion were recorded with a 5-point response scale ranging from 1 (not at all) to 5 (extremely) and scores for 'calm', 'relaxed', and 'peaceful' were reversed prior to analysis. The scale showed a good level of reliability across countries with Cronbach's alpha scores ranging from 0.71 to 0.92 (Table 1 ).

\subsubsection{Media exposure rate, attention, and content}

The rate of climate-related media exposure was measured by asking participants to indicate the average frequency at which they read or hear about climate change from various sources including TV news and programmes, printed and online newspapers, radio news and programmes, Facebook, Twitter, YouTube, books and magazines, and scientific journals, articles, and blogs. Responses were recorded on a 9-point scale ranging from 'never' to 'more than 10 times per day'. Participants' scores across these items were averaged to obtain a reliable aggregate indicator ( $\alpha$ range $=0.67-0.89$ ). A country-wise breakdown of the reliability indices for the media exposure rate measure is available as supplementary data (Supplementary Table 2). We also asked participants to indicate the amount of attention they pay to climate change-related information on a 4-point scale ranging from 'none' to 'a lot' (Slater \& Rasinski, 2005).

To capture the content of the information to which participants were being exposed, we asked them to indicate the frequency at which they read or hear about climate change causes and drivers, climate change impacts, and climate change actions and solutions. Responses to the media content questions were also recorded using the 9-point response scale used to measure overall climate-related media exposure rates.

\subsubsection{Social norms}

We measured perceived social norms with eight items. Four of these captured descriptive norms regarding negative emotional responses to climate change (e.g., "most people close to me are worried about the future effects of climate change") and the other four captured injunctive norms (e.g., "most people close to me think that one should be concerned about climate change"). We combined these items to obtain aggregate indicators of perceived descriptive ( $\alpha$ range $=0.63-0.84$ ) and injunctive norms ( $\alpha$ range $=0.48-0.86$ ) that surpassed the conventional reliability threshold $(\alpha=0.70$; Nunnally, 1970) in all but a very small minority of countries. A country-wise breakdown of the reliability indices for the perceived social norms measures is provided as supplementary data (Supplementary Table 3).

\subsubsection{Personal experience}


Experiences with extreme weather were measured with two items adopted from van der Linden (2014). Participants were asked to indicate how often they had experienced (a) flooding and (b) other extreme weather events (e.g., heatwaves, droughts, hurricanes, storms) in their local area over the last five years. Responses were recorded on a 5-point scale ranging from "never" to "more than 3 times". Scores on the two items were subsequently dichotomised to create indexes describing personal experiences with flooding and/or other extreme weather events $(0=$ no experience, 1 = experience). Respondents who indicated that they could not remember if they had experienced any such event were coded as missing.

\subsubsection{Pro-environmental behaviour and environmental activism}

Pro-environmental behaviour was measured with a multi-item index of sustainable consumption behaviours adapted from Ojala (2012). Participants were asked to indicate how often they engage in each of eight pro-environmental behaviours: (1) cycle or walk instead of driving, (2) restrain oneself from buying unneeded new clothes, (3) choose not to fly, (4) try to influence family and friends to act pro-environmentally, (5) save energy in the household, (6) take public transportation instead of the car, (7) avoid food waste, and (8) make climatefriendly food choices. Responses to these items were rated between " 1 = almost never" and " 5 = almost always". The aggregated scale surpassed the conventional reliability threshold ( $\alpha$ $=0.70$ ) in 22 out of 28 countries ( $\alpha$ range $=0.56-0.85$ ).

We also measured environmental activism by asking participants if they had attended a climate protest at any point in the past year up till the time of data collection. Responses to this question were coded as "No" = 0 and "Yes" = 1. A small minority (13.6\%) of the total sample indicated that they had attended a climate protest (Table 2).

\subsubsection{Mental wellbeing}

We measured mental wellbeing using the WHO-5 wellbeing index (WHO, 1998). The scale includes 5 items in which participants are asked to rate how often over the preceding two weeks: (1) they have felt cheerful and in good spirits, (2) they have felt calm and relaxed, (3) they have felt active and vigorous, (4) they woke up feeling fresh and rested, and (5) their life has been filled with things that interest them. Responses to these questions are recorded on a 6-point scale ranging from 0 (At no time) to 5 (All of the time). The scale items were aggregated to form a reliable measure across all the countries ( $\alpha$ range $=0.71-0.89$ ). Country-wise descriptive statistics for mental wellbeing are presented in Table 2.

\subsection{Analysis}

Due to the nested nature of the data (individuals within countries), we tested our hypotheses with hierarchical linear models using the $\mathrm{R}$ package Ime4 for mixed effects models (Bates et 
al., 2014). Level 1 fixed effects were individual-level variables: media exposure (rate, attention, content), perceived social norms (descriptive, injunctive), and extreme weather experiences, with country-level random intercepts added. In the first step of model-building, we estimated unconstrained models for each dependent variable with no predictors. These models showed that the grouping factor (country), explained approximately $7 \%$ variance in mental wellbeing, $9 \%$ variance in negative climate-related emotions, $15 \%$ variance in pro-environmental behaviour, and $23 \%$ variance in environmental activism. This demonstrates a significant clustering effect in the data.

Additionally, the analysis accounted for potential cross-national variation in how negative climate-related emotions predict the behavioural and wellbeing outcomes. Therefore, we estimated a model containing Level 1 predictors and random country-level intercepts only for each outcome variable (pro-environmental behaviour, environmental activism, and mental wellbeing) and compared that with another model containing the Level 1 predictors, random country-level intercepts and random slopes for negative climate-related emotions using a likelihood ratio test. The results of the model with random slopes for climate anxiety is reported where the likelihood ratio test shows that this model had a better fit to the data. Predictor variables were grand mean-centred prior to analysis and missing values were addressed with listwise deletion. The analyses controlled for participants' age and gender.

\section{Results}

\subsection{Preliminary observations}

A considerable proportion of participants reported strong negative emotional responses to climate change, but there was notable variation between countries (Table 1). The highest proportion of participants indicating that they were 'very' or 'extremely' worried about climate change was recorded in Spain (77.6\%) and the lowest proportion was recorded in Russia $(9.6 \%)$. The average proportion of participants indicating that they were 'very' or 'extremely' worried about climate change across the total sample was $46.8 \%$. As the samples are not nationally-representative, these observations do not necessarily reflect broader patterns of feeling about climate change in each country. Rather, they are presented here to illustrate the particular profile of individuals that volunteered to participate in the study.

Another striking pattern observed in the data was the degree of variation in ratings of anxiety and worry - emotions which are often used interchangeably when discussing climate-related emotions. Worry is a primary feature of anxiety and anxiety disorders (Newman et al., 2013; Rabner et al., 2017). However, a smaller proportion of people reported that they felt 'very' or 'extremely' anxious compared with 'very' or 'extremely' worried about climate change in 27 out of 28 countries. The mean difference in proportion between the two emotions (anxiety minus 
worry) was $19 \%$, but there was also marked variation across countries, with the largest difference observed in Spain (53\% in favour of worry) and the smallest difference observed in Nigeria $(0.4 \%$ in favour of worry). The only country in which a greater proportion of respondents indicated feeling 'very' or 'extremely' anxious than feeling 'very' or 'extremely' worried about climate change was Palestine (2.2\% in favour of anxiety). This could potentially be due to the words 'anxious' and 'worried' having a similar interpretation in Arabic.

\subsection{Predictors of negative climate-related emotions}

\subsubsection{Media exposure}

Contrary to our hypothesis $(\mathrm{H} 1)$, negative climate-related emotions were not significantly related to the overall rate of exposure to climate-related media (Table 3). However, attention to climate-related media positively predicted negative climate-related emotions $(\mathrm{H} 2)$. This suggests that merely encountering information about climate change may not trigger negative emotional responses in the absence of active engagement with the information. Further, we found that the rate of exposure to information about climate change impacts was positively related to negative climate-related emotions $(\mathrm{H} 3 \mathrm{~b})$, but exposure to information about climate change causes $(\mathrm{H} 3 \mathrm{a})$ and climate change solutions $(\mathrm{H} 3 \mathrm{c})$ did not show any significant effects. These results provide some support for the notion that the effect of media exposure on climate change anxiety is partly subject to the content of the information. In this case, information about climate change impacts appears to be the most important predictor of negative climate change-related emotions.

\subsubsection{Social norms}

Our hypothesis $(\mathrm{H} 4 \mathrm{a})$ was not supported as we found no significant relationship between descriptive norms and negative climate-related emotions (Table 3). However, we found support for our hypothesis (H4b) whereby injunctive norms positively predicted negative climate-related emotions. In other words, the degree of negative climate-related emotions expressed by participants was significantly associated with perceived social expectation to express negative feelings about climate change but not with the extent to which participants observed other people around them expressing negative feelings about climate change.

\subsubsection{Extreme weather experience}

Our hypothesis $(\mathrm{H} 5)$ was contradicted by the data (Table 3 ). We observed that prior experience of flooding in five years prior to the time of data collection did not significantly predict negative climate-related emotions. In contrast, experience of other extreme events such as heatwaves, droughts and hurricanes were inversely related to negative climaterelated emotions. In other words, people who had experienced extreme weather events other 
than flooding within five years prior to the time of data collection also reported lower levels of negative emotional responses to climate change.

3.3. Negative climate change-related emotions as predictors of pro-environmental behaviour, environmental activism and mental wellbeing

Overall, negative climate-related emotions had a significant positive relationship with proenvironmental behaviour ( $\mathrm{H6a})$ but not with environmental activism ( $\mathrm{H} 6 \mathrm{~b})$ - which was represented by participation in climate protests (Table 4). A likelihood ratio test showed that adding random slopes for negative climate-related emotions to the model predicting proenvironmental behaviour produced a significantly better fit to the data than a model with only random intercepts $\left(x^{2}=91.65, p<.001\right)$. This means that the relationship between negative climate change-related emotions and pro-environmental behaviour varies significantly across countries. Inspecting the plot of random slopes across countries (Figure 1) shows that negative climate-related emotions only had a significant positive relationship with proenvironmental behaviour in 13 countries (Australia, Brazil, Canada, Chile, Finland, Germany, Italy, Netherlands, Norway, Palestine, Portugal, Spain, and UAE).

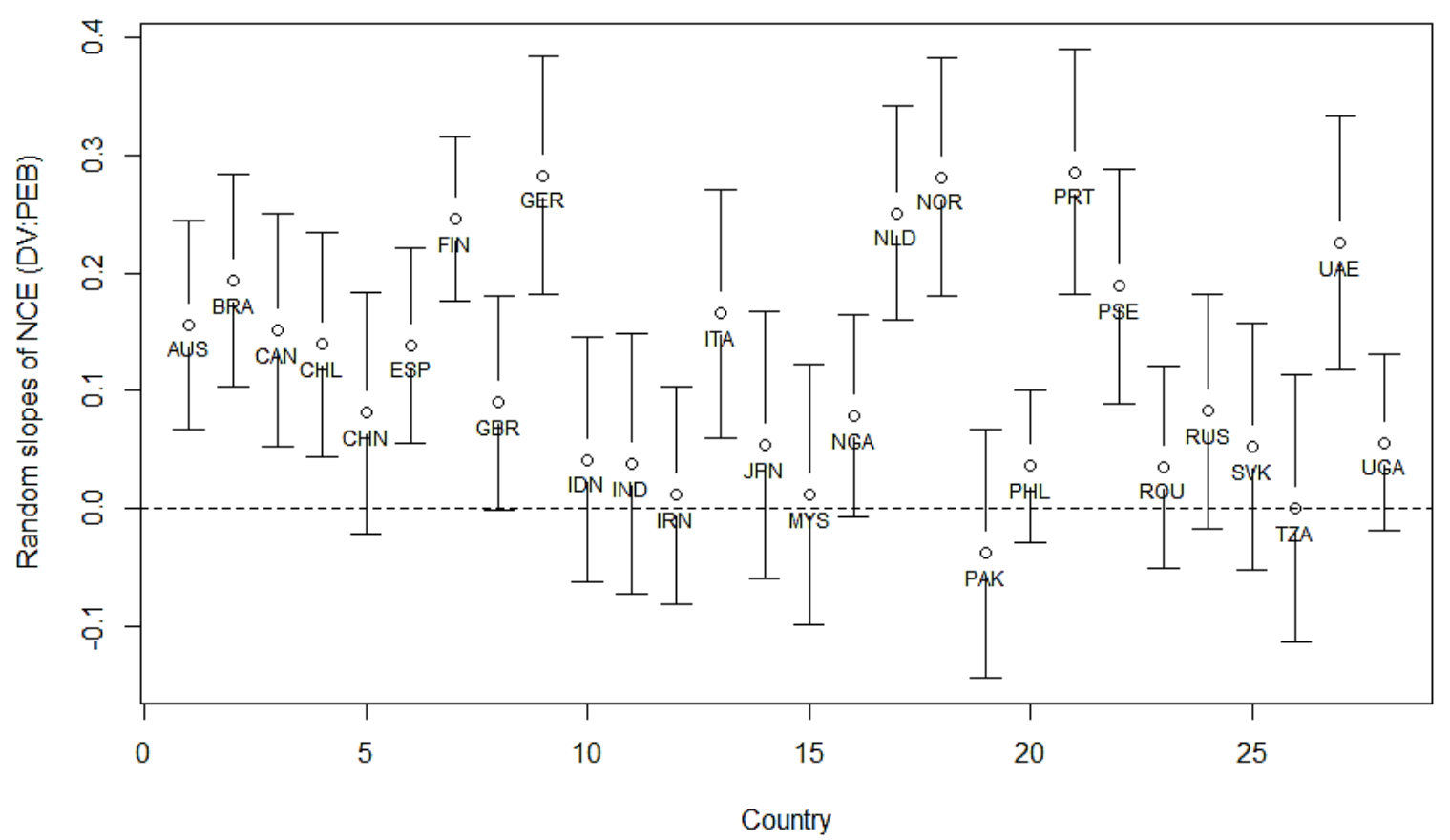

Figure 1. Random slopes of negative climate-related emotions (NCE) as a predictor of pro-environmental behaviour (PEB). Confidence intervals crossing zero indicates a non-significant relationship between NCE and PEB in the specified country.

Like pro-environmental behaviour, we found that adding random slopes for negative climaterelated emotions to the model predicting environmental activism showed a better fit to the data 
than a model only comprising random intercepts $\left(x^{2}=52.21, p<.001\right)$, which again suggests that the relationship between negative climate-related emotions and engagement in environmental activism varies significantly across countries. Inspecting the plot of random slopes across countries (Figure 2) revealed that negative climate-related emotions only significantly predicted engagement in environmental activism in 7 countries (Finland, Germany, Italy, Netherlands, Norway, Portugal, Spain).

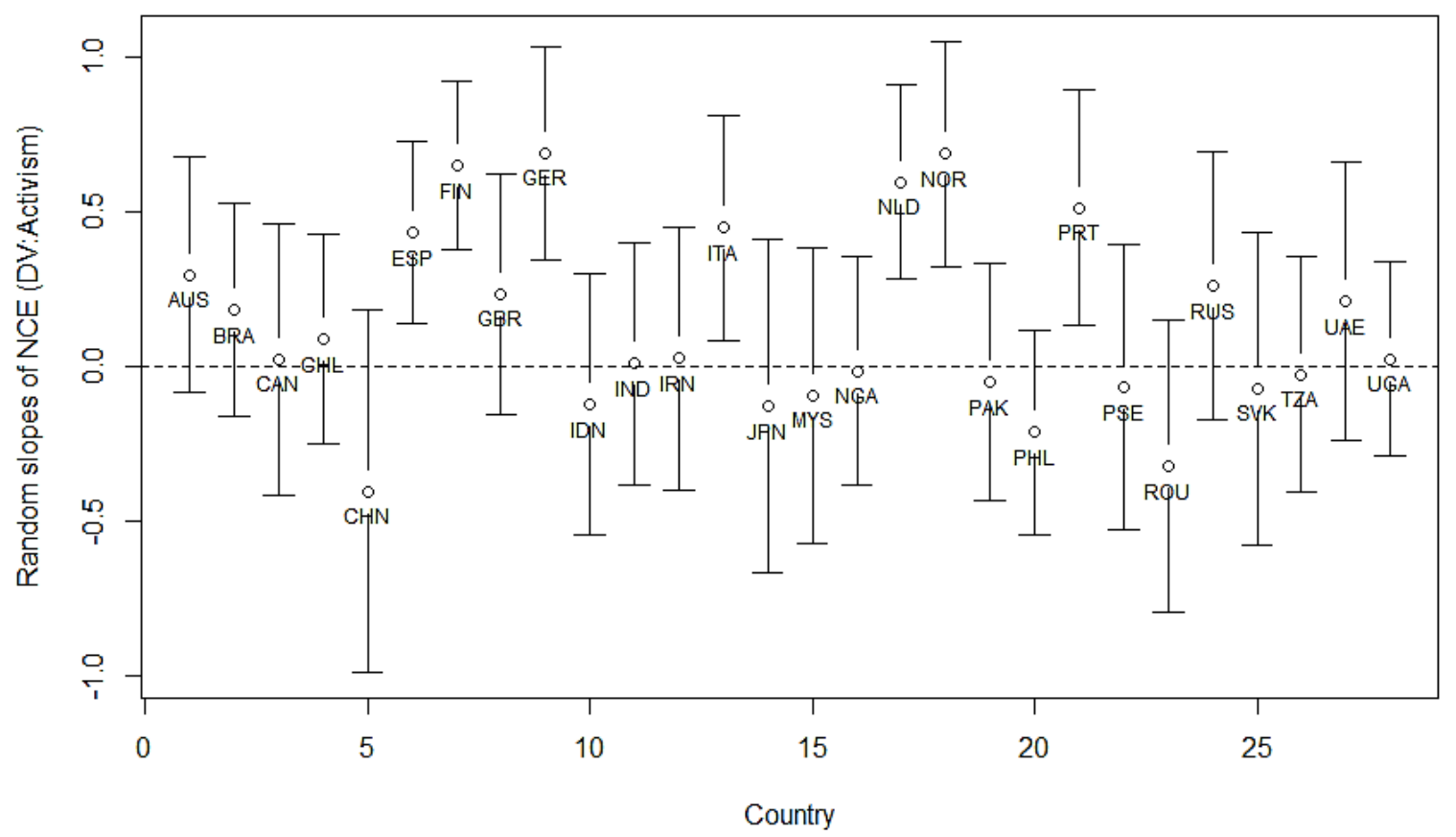

Figure 2. Random slopes of negative climate-related emotions (NCE) as a predictor of environmental activism (participation in climate protests). Confidence intervals crossing zero indicates a non-significant relationship between NCE and environmental activism in the specified country.

Finally, in support of our hypothesis ( $\mathrm{H} 7)$, we found that negative climate-related emotions had a significant inverse relationship with mental wellbeing (Table 4). However, adding random slopes for negative climate-related emotions also fit the data better than only having random intercepts in the model predicting mental wellbeing $\left(x^{2}=35.09, p<.001\right)$. This suggests that the relationship between negative climate-related emotions and mental wellbeing varies across countries. Inspecting the random slopes plot showed that, although the relationship between negative climate-related emotions and mental wellbeing was significant in every country represented in the dataset, the magnitude of the relationship varied significantly across countries (Figure 3). 


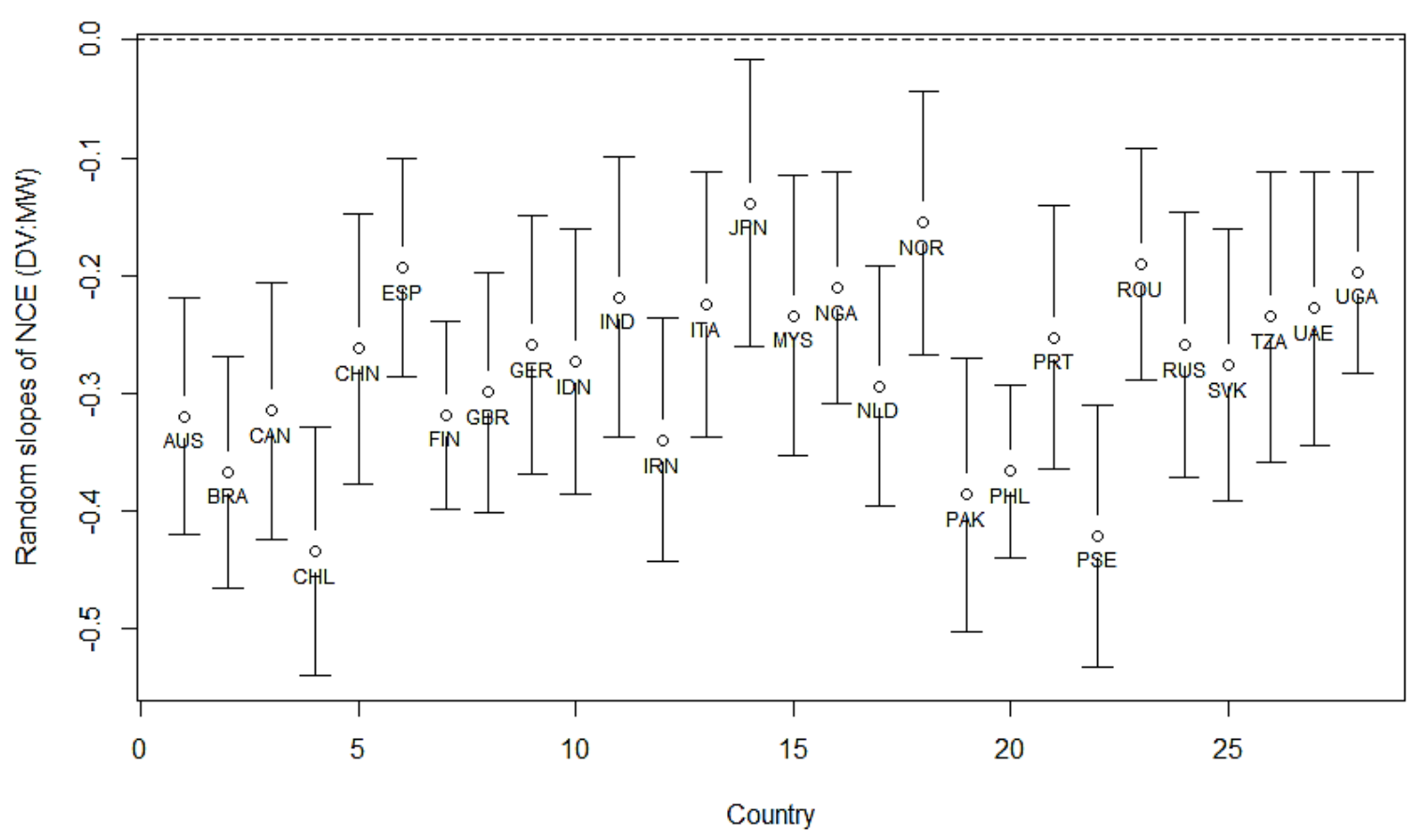

Figure 3. Random slopes of negative climate-related emotions (NCE) as a predictor of mental wellbeing.

\subsection{Supplementary observations}

Rate of exposure to climate change-related media only positively predicted engagement in environmental activism, while attention to climate change-related media positively predicted both pro-environmental behaviour and engagement in environmental activism (Table 4). Further, exposure to information about the causes of climate change positively predicted both pro-environmental behaviour and environmental activism. Exposure to information about climate change solutions predicted only engagement in environmental activism, while exposure to information about climate change impacts was not related to pro-environmental behaviour or engagement in environmental activism.

With respect to norms, pro-environmental behaviour was positively predicted by both descriptive and injunctive norms regarding expression of negative emotions toward climate change. Gender was also a significant predictor; with female respondents reporting greater engagement in pro-environmental behaviour than males.

Notably, overall rate of exposure to climate-related media, attention to climate-related media, and exposure to information about climate change solutions all positively predicted mental wellbeing. Perceived injunctive norms supporting expression of negative climate-related emotions, as well as personal experience with extreme weather also positively predicted 
mental wellbeing (Table 4). However, gender was negatively related with wellbeing. Female respondents reported significantly lower mental wellbeing, on average, than males.

\section{Discussion}

Emotions shape the way we process information and determine appropriate courses of action. They are consequently an integral element of how we engage with climate change (Davidson \& Kecinski, 2021). The number of people reporting psychological distress about the climate crisis has been rising in tandem with the growing visibility of adverse climate change impacts around the world. In this study, we explored plausible antecedents and outcomes of such emotional responses across a diverse range of national contexts. Specifically, we examined if and how negative emotional responses to climate change relate to media exposure, perceived social norms and personal experience. We also explored how negative climate-related emotions relate to pro-environmental behaviour, environmental activism and wellbeing.

\subsection{Implications}

\subsubsection{Media effects}

The role of climate change awareness as a precursor for negative climate-related emotions underlies a previous speculation that the prevalence of negative eco-emotions relates to increasing access or exposure to information about climate change (Clayton, 2020; Reser \& Swim, 2011; Stokols et al., 2009). This speculation is somewhat challenged by our finding that the overall rate of exposure to climate-related media alone does not significantly predict negative climate-related emotions. In fact, higher rates of exposure to climate-related media, especially content relating to climate change solutions was positively related to wellbeing. A plausible explanation for this is that exposure to climate-related media influences people's sense of efficacy about addressing the climate crisis (Maran \& Begotti, 2021), which is in turn linked to greater wellbeing (e.g., Karademas, 2006).

In a pluralistic media landscape (Busch \& Judick, 2021; W. Shi et al., 2020; Thaker \& Leiserowitz, 2014), it is unsurprising that negative climate-related emotions were more closely linked to the amount of attention people direct at climate change-related media, as well as the content of the information people consume. Given the cross-sectional design, the evidence from the current study is insufficient to establish the direction of causality between negative climate-related emotions and attention to climate-related media. However, theory and empirical evidence suggest a potential reciprocal relationship whereby attention to information about climate change heightens negative emotions about the issue on one hand (e.g., Ogunbode et al., 2020), and negative emotions elevate attention to climate change information on the other (e.g., Hmielowski et al., 2019; Yang \& Kahlor, 2013). 
Further, only exposure to information about climate change impacts had a significant relationship with negative climate-related emotions, whereas exposure to information about climate change causes or solutions did not show a significant relationship. We interpret this as an indication that the valence of new information about climate change impacts may be better matched to the pre-existing (negative) feelings people have about climate change (Bloodhart et al., 2019). In other words, impact-themed information may modulate people's worries about climate change more easily than cause or solutions information which have a greater likelihood of being neutral or opposed in valence to people's existing emotions.

\subsubsection{Social norms}

The current study also generated an important set of findings regarding the role of social norms as antecedents of negative climate-related emotions. We found that negative climaterelated emotions are positively related to injunctive norms or belief that significant others think that one ought to have a negative emotional response to climate change. Much focus has been directed at establishing the rationality of negative emotional responses to climate change (Verplanken et al., 2020; Verplanken \& Roy, 2013), but it is also important to understand the experience and expression of negative climate-related emotions as a normative phenomenon.

Emotions are fundamentally relational. This means that they emerge from social interactions; they are socially shared, and are shaped by social context (Bericat, 2015; Turner \& Stets, 2006; von Scheve \& Ismer, 2013). Social entanglements like shared values, culture, knowledge and identities create a motivation among individuals for emotion management, or entrainment, to match what is perceived to be the expected emotional response in specific social situations (Bianchi et al., 2016; Davidson \& Kecinski, 2021; He et al., 2016). Aligning one's personal emotions with collective emotional norms is important for belonging and solidarity (He et al., 2016). Further, emotion management by individuals creates and sustains group-level emotional climates, which in turn condition the general emotional dispositions of individual group members (Härtel et al., 2008).

Norgaard (2011) revealed how social context shapes the way people manage their emotional responses to ecological threats by examining the socially-constructed silence around climate change in a rural Norwegian community. In the context of her study, acknowledging the reality of climate change posed a threat of collective trauma - the disruption of Norway's economic prosperity which is strongly tied to oil production (Norgaard, 2006). Consequently, the prevailing social norms dictated collective denial and suppression climate change concern.

Unlike the people of Norgaard's (2011) rural Norwegian community, most people around the world, particularly young people and citizens of vulnerable countries facing disproportionate negative impacts from climate change (Harrington et al., 2016; Thiery et al., 2021), do not 
have a stake in preserving the status quo. von Scheve and Ismer (2013) argue that the calibration of emotions within collectives is partly rooted in shared cognitive appraisal structures reflecting collective values, goals and experiences. The international expansion of climate activism has been buoyed by shared experiences of ongoing climate change impacts and of negative climate-related emotions like fear, worry and anger (Halstead et al., 2021; Kleres \& Wettergren, 2017). As climate activism becomes more salient in public life, and greater number of people are able to identify with climate activists and activist groups, this is likely to have knock-on effects on general perceived normative expectations about appropriate emotional responses to the climate crisis. A plausible pathway for these effects is through youth climate activists' modelling of anger and hope as an antidote to inaction on key issues (Kleres \& Wettergren, 2017).

\subsubsection{Personal experience}

The two indices of personal experience with extreme weather assessed in this study showed counter-intuitive relationships with negative climate-related emotions. Contrary to previous findings (e.g., Bergquist et al., 2019; Spence et al., 2011; Zanocco et al., 2018), prior flooding experience did not predict negative climate-related emotions. Experience with other extreme weather events was inversely related to negative climate-related emotions. Considering that extreme weather experiences typically have a negative emotional valence, it is reasonable to expect them to be directly related with negative climate-related emotions. Yet, there are important nuances in how people interpret their extreme weather experiences including politically-motivated biased cognition (Bruine de Bruin et al., 2014; Ogunbode et al., 2017), and the fact that climate change is only one of several interpretive lenses with which people can choose to make sense of their experiences (Reser et al., 2014). Further, the degree of distress evoked by extreme weather experiences is modulated by people's ability to cope with adverse impacts (Ogunbode et al., 2019), which may in turn translate to the level of negative emotions they express about climate change. In other words, the relationships we observed between extreme weather experience and negative climate-related emotions in this study may be explained by any combination of the specific profile of political orientations, causal/sensemaking interpretive lenses, and coping capacities of the individuals represented in our sample. A more nuanced investigation of the extreme weather experience and negative climate-related emotions relationship was beyond the scope of this study. Nonetheless, there is a need for more purposive inquiry into how extreme weather experiences shape responses to climate change using culturally-diverse samples to determine which findings broadly generalise (Sisco, 2021). 
4.1.4. Negative climate-related emotions as predictors of pro-environmental action and wellbeing

Finally, this study provided a unique opportunity to juxtapose how negative climate-related emotions predict different domains of environmentally-significant behaviour, and mental wellbeing in different countries. As expected, negative emotions were, overall, positively related to private-sphere pro-environmental behaviours, including actions like saving energy at home, using public transportation, and avoiding food waste. This reflects the well-known role of negative emotions as motivation for action (Weber, 2006). However, negative climaterelated emotions only significantly predicted pro-environmental behaviour in 13 out of 28 countries and did not significantly predict environmental activism overall. Further, all the countries in which a significant link was observed between negative climate-related emotions and environmental activism were European, democratic, and relatively affluent.

Engagement in pro-environmental action is one of the most widely advocated strategies for alleviating climate anxiety (Baudon \& Jachens, 2021), but our findings highlight the need to consider contextual barriers to channelling negative emotions into climate action. Feelings about climate change more readily translate to pro-environmental action among privileged groups, such as people with high socioeconomic status (Eom et al., 2018). In many parts of the world, particularly in countries of the Global South, people may be unable to engage in climate action due to having insufficient knowledge, facing financial or political barriers, or simply lacking opportunities (Deane, 2009; González-Hernández et al., 2019; Seth, 2021; Simpson et al., 2021).

Importantly, the barriers to climate action do not stop people's anxieties about the climate crisis from negatively impacting their mental health and wellbeing. As our data shows, negative climate-related emotions had a significant inverse relationship with mental wellbeing in all 28 countries irrespective of differences in national culture, politics or wealth. Here, we cannot completely rule out a possibility that heightened negative climate-related emotions among our sample is simply a manifestation, rather than a cause, of compromised mental wellbeing (Ogunbode et al., 2021) as heightened worry can be symptomatic of a range of common mental health disorders (Hirsch \& Mathews, 2012). However, a recent longitudinal study has also demonstrated a negative effect of climate change concern on psychological wellbeing among a national sample of New Zealanders over the course of a year (McBride et al., 2021). We therefore advocate an ethic of care in the deployment of emotive climate change engagement strategies. Climate change advocates have a responsibility to ensure that their efforts at promoting climate action do not end with activating people's emotions about climate 
change. Appropriate support must also be provided to minimise potential harmful effects of negative climate-related emotions on people's wellbeing.

\subsection{Limitations}

The cross-sectional nature of the current research precludes causal inferences about the relationships among the factors we investigated. Further research using experimental and/or longitudinal designs is needed to better establish the role of negative climate-related emotions as a pathway for indirect wellbeing impacts from climate change.

A further limitation pertains to the timing of data collection, which was unavoidably impacted by the COVID-19 pandemic. Data were gathered in three countries - India, Palestine and the UAE under different circumstances than in the other countries where data collection was completed before the imposition of national lockdowns. Research continues to emerge showing the negative impact of the COVID-19 crisis on people's mental health and wellbeing around the world (Chen et al., 2021; Hossain et al., 2021; Singh et al., 2020). This raises a question about the degree to which the data from the three countries might reflect unusually elevated levels of anxiety or lower levels of mental wellbeing. Our analysis did not reveal any significant differences in the pattern of results obtained from the samples recruited before and after the onset of the pandemic. Further, the COVID-19 affected samples are only a small proportion of the overall dataset. Therefore, any impact of COVID-19 is unlikely to have significantly influenced the main findings of the study.

Lastly, our samples are not representative of the countries from which they were drawn. Due to our reliance on university research participant pools and opportunity sampling, the total sample over-represents female, young, educated individuals and possibly people with high engagement with climate change who self-selected into the study. While we controlled for the effects of gender and age in our analyses, it is still possible that the effects of negative climaterelated emotions manifest differently for the demographic sub-groups that are over-/underrepresented in the study. Therefore, replication with representative national samples is needed to determine the degree to which our findings generalise more broadly.

\section{Conclusion}

This study is the most international investigation conducted to date on the antecedents of negative climate-related emotions, and how negative climate-related emotions relate to proenvironmental action and mental wellbeing. We found that negative emotional responses to climate change are related to the nature of information people receive through the media. Not the mere volume of media exposure, but the content of the information and the amount of attention people pay to it. Information about climate change impacts appears more strongly 
linked to negative climate-related emotions than information about climate change causes or solutions. Interestingly, the overall rate of exposure to climate change-related information is positively linked to mental wellbeing; potentially because some of the information people consume increases perceived efficacy about addressing the climate crisis. Perceived social expectations about emotional responding to climate change also appear to have a role in determining how people experience negative climate-related emotions.

Importantly, our data indicates that the way negative feelings about climate change relate to pro-environmental action differs across countries. Significant relationships between negative climate-related emotions and the two indices of pro-environmental action we examined were largely exclusive to Western and relatively affluent countries. In contrast, negative climaterelated emotions had a significant inverse relationship with mental wellbeing in all 28 countries, suggesting that people's climate-related anxieties can undermine their mental wellbeing irrespective of where they live, and the social/political affordances enabled (or not) by their country of residence.

Understanding of the inter-connections between climate change and mental wellbeing is at an early stage of development (Romeu, 2021). The current study provides an important foundation for a more global outlook on the significance of climate-related emotions for proenvironmental action and wellbeing. Little systematic evidence currently exists regarding the wellbeing implications of climate-related emotions, especially in the Global South. However, as our data suggests, negative climate-related emotions have broad international significance as a plausible challenge to mental wellbeing. Therefore, greater priority needs to be accorded to developing a correspondingly broad understanding of the scope, nature and distribution of wellbeing impacts potentially arising from negative climate-related emotions.

\section{References}

Bates, D., Maechler, M., Bolker, B., \& Walker, S. (2014). Ime4: linear mixed-effects models using S4 classes. R package version 1.1-6. In $R$. https://doi.org/http://CRAN.Rproject.org/package $=$ Ime 4

Baudon, P., \& Jachens, L. (2021). A Scoping Review of Interventions for the Treatment of Eco-Anxiety. International Journal of Environmental Research and Public Health 2021, Vol. 18, Page 9636, 18(18), 9636. https://doi.org/10.3390/IJERPH18189636

Bergquist, M., Nilsson, A., \& Schultz, P. W. (2019). Experiencing a severe weather event increases concern about climate change. Frontiers in Psychology, 10, 22. https://doi.org/10.3389/fpsyg.2019.00220

Bericat, E. (2015). The sociology of emotions: Four decades of progress: Current Sociology, 64(3), 491-513. https://doi.org/10.1177/0011392115588355 
Bianchi, A. J., Ruch, A. M., Ritter, M. J., \& Kim, J. H. (2016). Emotion Management: Unexpected Research Opportunities. Sociology Compass, 10(2), 172-183. https://doi.org/10.1111/SOC4.12340

Bloodhart, B., Swim, J. K., \& Dicicco, E. (2019). "Be Worried, be VERY Worried:" Preferences for and Impacts of Negative Emotional Climate Change Communication. Frontiers in Communication, 3, 63. https://doi.org/10.3389/fcomm.2018.00063

Bouman, T., Verschoor, M., Albers, C. J., Böhm, G., Fisher, S. D., Poortinga, W., Whitmarsh, L., \& Steg, L. (2020). When worry about climate change leads to climate action: How values, worry and personal responsibility relate to various climate actions. Global $\begin{array}{lll}\text { Environmental Change, } & 62, & 102061 .\end{array}$ https://doi.org/10.1016/J.GLOENVCHA.2020.102061

Bruine de Bruin, W., Wong-Parodi, G., \& Morgan, M. G. (2014). Public perceptions of local flood risk and the role of climate change. Environment Systems and Decisions, 34(4), 591-599. https://doi.org/10.1007/s10669-014-9513-6

Busch, T., \& Judick, L. (2021). Climate change-that is not real! A comparative analysis of climate-sceptic think tanks in the USA and Germany. Climatic Change, 164(1-2), 1-23. https://doi.org/10.1007/S10584-021-02962-Z/FIGURES/1

Chen, J., Farah, N., Dong, R. K., Chen, R. Z., Xu, W., Yin, J., Chen, B. Z., Delios, A. Y., Miller, S., Wan, X., Ye, W., \& Zhang, S. X. (2021). Mental Health during the COVID-19 Crisis in Africa: A Systematic Review and Meta-Analysis. International Journal of Environmental Research and Public Health 2021, Vol. 18, Page 10604, 18(20), 10604. https://doi.org/10.3390/IJERPH182010604

Cialdini, R. B., Kallgren, C. A., \& Reno, R. R. (1991). A focus theory of normative conduct: A theoretical refinement and re-evaluation of the role of norms in human behavior. Advances in Experimental Social Psychology, 24(C), 201-234. https://doi.org/10.1016/S0065-2601(08)60330-5

Clayton, S. (2020). Climate anxiety: Psychological responses to climate change. Journal of Anxiety Disorders, 74, 102263. https://doi.org/10.1016/j.janxdis.2020.102263

Clayton, S., \& Karazsia, B. T. (2020). Development and validation of a measure of climate change anxiety. Journal of Environmental Psychology, 69, 101434. https://doi.org/10.1016/j.jenvp.2020.101434

Davidson, D. J., \& Kecinski, M. (2021). Emotional pathways to climate change responses. Wiley Interdisciplinary Reviews: Climate Change, e751. https://doi.org/10.1002/WCC.751

Deane, J. (2009). Least responsible, most affected, least informed: public understanding of climate change in Africa. In Africa Talks Climate. BBC World Service Trust. http://www.bbc.co.uk/mediaaction/publicationsandpress/research africa talks climate. $\underline{\mathrm{html}}$

Dessai, S., \& Sims, C. (2010). Public perception of drought and climate change in southeast England. Environmental Hazards, 9(4), 340-357. https://doi.org/10.3763/ehaz.2010.0037

Drew, D., \& Weaver, D. (2016). Media Attention, Media Exposure, and Media Effects: Journalism and Mass Communication Quarterly, 67(4), 740-748. https://doi.org/10.1177/107769909006700428 
Ehlers, A., \& Clark, D. M. (2000). A cognitive model of posttraumatic stress disorder. Behaviour Research and Therapy, 38(4), 319-345. https://doi.org/10.1016/S00057967(99)00123-0

Eom, K., Kim, H. S., \& Sherman, D. K. (2018). Social class, control, and action: Socioeconomic status differences in antecedents of support for pro-environmental action. Journal of Experimental Social Psychology, 77, 60-75. https://doi.org/10.1016/J.JESP.2018.03.009

Evensen, D., Whitmarsh, L., Bartie, P., Devine-Wright, P., Dickie, J., Varley, A., Ryder, S., \& Mayer, A. (2021). Effect of "finite pool of worry" and COVID-19 on UK climate change perceptions. Proceedings of the National Academy of Sciences of the United States of America, 118(3). https://doi.org/10.1073/pnas.2018936118

Fernández-Llamazares, Á., Méndez-López, M. E., Díaz-Reviriego, I., McBride, M. F., Pyhälä, A., Rosell-Melé, A., \& Reyes-García, V. (2015). Links between media communication and local perceptions of climate change in an indigenous society. Climatic Change, 131(2), 307-320. https://doi.org/10.1007/s10584-015-1381-7

Gerbner, G., Gross, L., Morgan, M., Signorielli, N., \& Shanahan, J. (2002). Growing up with television: Cultivation Processes. In Media Effects: Advances in Theory and Research.

Gibson, K. E., Barnett, J., Haslam, N., \& Kaplan, I. (2020). The mental health impacts of climate change: Findings from a Pacific Island atoll nation. Journal of Anxiety Disorders, 73, 102237. https://doi.org/10.1016/j.janxdis.2020.102237

González-Hernández, D. L., Meijles, E. W., \& Vanclay, F. (2019). Household Barriers to Climate Change Action: Perspectives from Nuevo Leon, Mexico. Sustainability 2019, Vol. 11, Page 4178, 11(15), 4178. https://doi.org/10.3390/SU11154178

Halstead, F., Parsons, L. R., Dunhill, A., \& Parsons, K. (2021). A journey of emotions from a young environmental activist. Area. https://doi.org/10.1111/AREA.12745

Harrington, L. J., Frame, D. J., Fischer, E. M., Hawkins, E., Joshi, M., \& Jones, C. D. (2016). Poorest countries experience earlier anthropogenic emergence of daily temperature extremes. Environmental Research Letters, 11(5), 055007. https://doi.org/10.1088/1748$\underline{9326 / 11 / 5 / 055007}$

Härtel, C. E. J., Gough, H., \& Härtel, G. F. (2008). Work-group emotional climate, emotion management skills, and service attitudes and performance. Asia Pacific Journal of Human Resources, 46(1). https://doi.org/10.1177/1038411107086541

He, S., Zheng, X., Zeng, D., Luo, C., \& Zhang, Z. (2016). Exploring entrainment patterns of human emotion in social media. PLOS ONE, 11(3), e0150630. https://doi.org/10.1371/JOURNAL.PONE.0150630

Hirsch, C. R., \& Mathews, A. (2012). A cognitive model of pathological worry. Behaviour Research and Therapy, 50(10), 636-646. https://doi.org/10.1016/j.brat.2012.06.007

Hmielowski, J. D., Donaway, R., \& Wang, M. Y. (2019). Environmental risk information seeking: The differential roles of anxiety and hopelessness. Environmental Communication, 13(7), 894-908. https://doi.org/10.1080/17524032.2018.1500926

Hogg, M. A., \& Reid, S. A. (2006). Social identity, self-categorization, and the communication of group norms. Communication Theory, 16(1), 7-30. 
Hornsey, M. J., \& Fielding, K. S. (2016). A cautionary note about messages of hope: Focusing on progress in reducing carbon emissions weakens mitigation motivation. Global Environmental Change, 39, 26-34. https://doi.org/10.1016/J.GLOENVCHA.2016.04.003

Hossain, M. M., Rahman, M., Trisha, N. F., Tasnim, S., Nuzhath, T., Hasan, N. T., Clark, H., Das, A., McKyer, E. L. J., Ahmed, H. U., \& Ma, P. (2021). Prevalence of anxiety and depression in South Asia during COVID-19: A systematic review and meta-analysis. Heliyon, 7(4), e06677. https://doi.org/10.1016/J.HELIYON.2021.E06677

Houston, J. B., First, J., \& Danforth, L. M. (2018). Student Coping with the Effects of Disaster Media Coverage: A Qualitative Study of School Staff Perceptions. School Mental Health, 1-13. https://doi.org/10.1007/s12310-018-9295-y

Houston, J. B., Spialek, M. L., \& First, J. (2018). Disaster Media Effects: A Systematic Review and Synthesis Based on the Differential Susceptibility to Media Effects Model. Journal of Communication, 68(4), 734-757. https://doi.org/10.1093/joc/jay023

Karademas, E. C. (2006). Self-efficacy, social support and well-being: The mediating role of optimism. Personality and Individual Differences, 40(6), 1281-1290.

Kleres, J., \& Wettergren, Å. (2017). Fear, hope, anger, and guilt in climate activism. Social Movement Studies, 16(5), 507-519. https://doi.org/10.1080/14742837.2017.1344546

Konisky, D. M., Hughes, L., \& Kaylor, C. H. (2016). Extreme weather events and climate change concern. Climatic Change, 134(4), 533-547. https://doi.org/10.1007/s10584$\underline{015-1555-3}$

Lee, J., \& Cho, M. (2019). The effects of consumers' media exposure, attention, and credibility on pro-environmental behaviors. Journal of Promotion Management, 26(3), 434-455. https://doi.org/10.1080/10496491.2019.1699629

Leiserowitz, A., Carman, J., Buttermore, N., Wang, X., Rosenthal, S., Marlon, J. R., \& Mulcahy, K. (2021). International Public Opinion on Climate Change. Yale Program on Climate Change Communication.

https://climatecommunication.yale.edu/publications/international-public-opinion-onclimate-change/4/

Maran, D. A., \& Begotti, T. (2021). Media exposure to climate change, anxiety, and efficacy beliefs in a sample of Italian university students. International Journal of Environmental Research and Public Health, 18(17), 9358. https://doi.org/10.3390/ijerph18179358

Marks, E., Hickman, C., Pihkala, P., Clayton, S., Lewandowski, E. R., Mayall, E. E., Wray, B., Mellor, C., \& van Susteren, L. (2021). Young People's Voices on Climate Anxiety, Government Betrayal and Moral Injury: A Global Phenomenon. SSRN Electronic Journal. https://doi.org/10.2139/SSRN.3918955

Marx, S. M., Weber, E. U., Orlove, B. S., Leiserowitz, A., Krantz, D. H., Roncoli, C., \& Phillips, J. (2007). Communication and mental processes: Experiential and analytic processing of uncertain climate information. Global Environmental Change, 17, 47-58. https://doi.org/10.1016/i.gloenvcha.2006.10.004

McBride, S. E., Hammond, M. D., Sibley, C. G., \& Milfont, T. L. (2021). Longitudinal relations between climate change concern and psychological wellbeing. Journal of Environmental Psychology, 78, 101713. https://doi.org/10.1016/J.JENVP.2021.101713 
McDonald, R., Chai, H. Y., \& Newell, B. (2015). Personal experience and the "psychological distance" of climate change: An integrative review. In Journal of Environmental Psychology (Vol. 44, pp. 109-118). https://doi.org/10.1016/j.jenvp.2015.10.003

Myers, T. A., Maibach, E. W., Roser-Renouf, C., Akerlof, K., \& Leiserowitz, A. (2013). The relationship between personal experience and belief in the reality of global warming. Nature Climate Change, 3(4), 343-347. https://doi.org/10.1038/nclimate1754

Newman, M. G., Llera, S. J., Erickson, T. M., Przeworski, A., \& Castonguay, L. G. (2013). Worry and Generalized Anxiety Disorder: A Review and Theoretical Synthesis of Evidence on Nature, Etiology, Mechanisms, and Treatment. Annual Review of Clinical Psychology, 9, 275-297. https://doi.org/10.1146/ANNUREV-CLINPSY-050212-185544

Norgaard, K. M. (2006). "We don't really want to know”: Environmental justice and socially organized denial of global warming in Norway. Organization \& Environment, 19(3), 347370. https://doi.org/10.1177/1086026606292571

Norgaard, K. M. (2011). Living in Denial: Climate Change, Emotions, and Everyday Life. MIT Press.

Nunnally, J. C. (1970). Introduction to Psychological Measurement. McGraw-Hill, New York.

Ogunbode, C. A., Demski, C., Capstick, S. B., \& Sposato, R. G. (2019). Attribution matters: revisiting the link between extreme weather experience and climate change mitigation responses. Global Environmental Change, 54, 31-39. https://doi.org/10.1016/j.gloenvcha.2018.11.005

Ogunbode, C. A., Doran, R., \& Böhm, G. (2020a). Exposure to the IPCC special report on 1.5 ${ }^{\circ} \mathrm{C}$ global warming is linked to perceived threat and increased concern about climate change. Climatic Change, 158(3-4), 361-375. https://doi.org/10.1007/s10584-01902609-0

Ogunbode, C. A., Doran, R., \& Böhm, G. (2020b). Individual and local flooding experiences are differentially associated with subjective attribution and climate change concern. Climatic Change, 162(4), 2243-2255. https://doi.org/10.1007/s10584-020-02793-4

Ogunbode, C. A., Liu, Y., \& Tausch, N. (2017). The moderating role of political affiliation in the link between flooding experience and preparedness to reduce energy use. Climatic Change, 145(3), 445-458. https://doi.org/10.1007/s10584-017-2089-7

Ogunbode, C. A., Pallesen, S., Böhm, G., Doran, R., Bhullar, N., Aquino, S., Marot, T., Schermer, J. A., Wlodarczyk, A., Lu, S., Jiang, F., Salmela-Aro, K., Hanss, D., Maran, D. A., Ardi, R., Chegeni, R., Tahir, H., Ghanbarian, E., Park, J., ... Lomas, M. J. (2021). Negative emotions about climate change are related to insomnia symptoms and mental health: Cross-sectional evidence from 25 countries. Current Psychology, 1-10. https://doi.org/10.1007/s12144-021-01385-4

Ojala, M. (2012). Hope and climate change: The importance of hope for environmental engagement among young people. Environmental Education Research, 18(5), 625-642. https://doi.org/10.1080/13504622.2011.637157

Ojala, M., Cunsolo, A., Ogunbode, C. A., \& Middleton, J. (2021). Anxiety, Worry, and Grief in a Time of Environmental and Climate Crisis: A Narrative Review. Annual Review of Environment and Resources, 46(1), 35-58. https://doi.org/10.1146/annurev-environ$\underline{012220-022716}$ 
Pfefferbaum, B., Newman, E., Nelson, S. D., Nitiéma, P., Pfefferbaum, R. L., \& Rahman, A. (2014). Disaster Media Coverage and Psychological Outcomes: Descriptive Findings in the Extant Research. Current Psychiatry Reports, 16(9), 464. https://doi.org/10.1007/s11920-014-0464-x

Pinkala, P. (2020). Anxiety and the Ecological Crisis: An Analysis of Eco-Anxiety and Climate Anxiety. Sustainability, 12(19), 7836. https://doi.org/10.3390/su12197836

Rabner, J., Mian, N. D., Langer, D. A., Comer, J. S., \& Pincus, D. (2017). The Relationship Between Worry and Dimensions of Anxiety Symptoms in Children and Adolescents. Behavioural and Cognitive Psychotherapy, 45(2), 124-138. https://doi.org/10.1017/S1352465816000448

Ray, S. J. (2021). Climate Anxiety Is an Overwhelmingly White Phenomenon. Scientific American. https://www.scientificamerican.com/article/the-unbearable-whiteness-ofclimate-anxiety/

Reser, J. P., Bradley, G. L., \& Ellul, M. C. (2014). Encountering climate change: "Seeing" is more than "believing." Wiley Interdisciplinary Reviews: Climate Change, 5(4), 521-537. https://doi.org/10.1002/wcc.286

Reser, J. P., \& Swim, J. (2011). Adapting to and coping with the threat and impacts of climate change. American Psychologist, 66(4), 277-289. https://doi.org/10.1037/a0023412

Reyes, M. E. S., Carmen, B. P. B., Luminarias, M. E. P., Mangulabnan, S. A. N. B., \& Ogunbode, C. A. (2021). An investigation into the relationship between climate change anxiety and mental health among Gen Z Filipinos. Current Psychology 2021, 1-9. https://doi.org/10.1007/S12144-021-02099-3

Romeu, D. (2021). Is climate change a mental health crisis? BJPsych Bulletin, 45(4), 243245. https://doi.org/10.1192/BJB.2021.30

Sampei, Y., \& Aoyagi-Usui, M. (2009). Mass-media coverage, its influence on public awareness of climate-change issues, and implications for Japan's national campaign to reduce greenhouse gas emissions. Global Environmental Change, 19(2), 203-212. https://doi.org/10.1016/j.gloenvcha.2008.10.005

Seth, P. (2021, March 5). Breaking Down Barriers to Climate Action in South Asia. AVPN Blog. https://avpn.asia/blog/breaking-down-barriers-to-climate-action-in-south-asia/

Shi, J., Visschers, V. H. M., Siegrist, M., \& Arvai, J. (2016). Knowledge as a driver of public perceptions about climate change reassessed. Nature Climate Change, 6(8), 759-762. https://doi.org/10.1038/nclimate2997

Shi, W., Fu, H., Wang, P., Chen, C., \& Xiong, J. (2020). \#Climatechange vs. \#Globalwarming: Characterizing Two Competing Climate Discourses on Twitter with Semantic Network and Temporal Analyses. International Journal of Environmental Research and Public Health 2020, Vol. 17, Page 1062, 17(3), 1062. https://doi.org/10.3390/IJERPH17031062

Simpson, N. P., Andrews, T. M., Krönke, M., Lennard, C., Odoulami, R. C., Ouweneel, B., Steynor, A., \& Trisos, C. H. (2021). Climate change literacy in Africa. Nature Climate Change 2021 11:11, 11(11), 937-944. https://doi.org/10.1038/s41558-021-01171-x

Singh, S., Roy, D., Sinha, K., Parveen, S., Sharma, G., \& Joshi, G. (2020). Impact of COVID19 and lockdown on mental health of children and adolescents: A narrative review with 
$\begin{array}{llll}\text { recommendations. Psychiatry } & \text { Research, } & 293, & 113429 .\end{array}$ https://doi.org/10.1016/J.PSYCHRES.2020.113429

Sisco, M. R. (2021). The effects of weather experiences on climate change attitudes and behaviors. Current Opinion in Environmental Sustainability, 52, 111-117. https://doi.org/10.1016/J.COSUST.2021.09.001

Slater, M. D., \& Rasinski, K. A. (2005). Media Exposure and Attention as Mediating Variables Influencing Social Risk Judgments. Journal of Communication, 55(4), 810-827. https://doi.org/10.1111/J.1460-2466.2005.TB03024.X

Spence, A., Poortinga, W., Butler, C., \& Pidgeon, N. F. (2011). Perceptions of climate change and willingness to save energy related to flood experience. Nature Climate Change, 1(1), 46-49. https://doi.org/10.1038/nclimate1059

Spielberger, C. D. (1983). State-Trait Anxiety Inventory for Adults. MindGarden.

Stanley, S. K., Hogg, T. L., Leviston, Z., \& Walker, I. (2021). From anger to action: Differential impacts of eco-anxiety, eco-depression, and eco-anger on climate action and wellbeing. The Journal of Climate Change and Health, 1, 100003. https://doi.org/10.1016/J.JOCLIM.2021.100003

Stern, P. C. (2000). Toward a coherent theory of environmentally significant behavior. Journal of Social Issues, 56(3), 407-424.

Stokols, D., Misra, S., Runnerstrom, M. G., \& Hipp, J. A. (2009). Psychology in an age of ecological crisis: From personal angst to collective action. American Psychologist, 64(3), 181-193. https://doi.org/10.1037/a0014717

Thaker, J., \& Leiserowitz, A. (2014). Shifting discourses of climate change in India. Climatic Change, 123(2), 107-119. https://doi.org/10.1007/s10584-014-1059-6

Thaker, J., Zhao, X., \& Leiserowitz, A. (2017). Media Use and Public Perceptions of Global Warming in India. Environmental Communication, 11(3), 353-369. https://doi.org/10.1080/17524032.2016.1269824

Thiery, W., Lange, S., Rogelj, J., Schleussner, C. F., Gudmundsson, L., Seneviratne, S. I., Andrijevic, M., Frieler, K., Emanuel, K., Geiger, T., Bresch, D. N., Zhao, F., Willner, S. N., Büchner, M., Volkholz, J., Bauer, N., Chang, J., Ciais, P., Dury, M., ... Wada, Y. (2021). Intergenerational inequities in exposure to climate extremes. Science, 374(6564), 158160.

https://doi.org/10.1126/SCIENCE.ABI7339/SUPPL FILE/SCIENCE.ABI7339 SM.PDF

Turner, J. H., \& Stets, J. E. (2006). Sociological theories of human emotions. Annual Review of Sociology, 32, 25-52. https://doi.org/10.1146/ANNUREV.SOC.32.061604.123130

van der Linden, S. (2014). The social-psychological determinants of climate change risk perceptions: Towards a comprehensive model. Journal of Environmental Psychology, 41, 112-124. https://doi.org/10.1016/i.jenvp.2014.11.012

van Valkengoed, A. M., \& Steg, L. (2019). Meta-analyses of factors motivating climate change adaptation behaviour. Nature Climate Change, 9(2), 158-163. https://doi.org/10.1038/s41558-018-0371-y 
Verplanken, B., Marks, E., \& Dobromir, A. I. (2020). On the nature of eco-anxiety: How constructive or unconstructive is habitual worry about global warming? Journal of Environmental Psychology, 72, 101528. https://doi.org/10.1016/i.jenvp.2020.101528

Verplanken, B., \& Roy, D. (2013). "My worries are rational, climate change is not": Habitual ecological worrying is an adaptive response. PLOS ONE, 8(9), e74708. https://doi.org/10.1371/journal.pone.0074708

von Scheve, C., \& Ismer, S. (2013). Towards a Theory of Collective Emotions: Emotion Review, 5(4), 406-413. https://doi.org/10.1177/1754073913484170

Whitmarsh, L. (2008). Are flood victims more concerned about climate change than other people? The role of direct experience in risk perception and behavioural response. Journal of Risk Research, 11(3), 351-374. https://doi.org/10.1080/13669870701552235

WHO. (1998). Wellbeing measures in primary healthcare/The DEPCARE project. World Health Organisation Regional Office for Europe: Copenhagen.

Wullenkord, M. C., Tröger, J., Hamann, K. R. S., Loy, L. S., \& Reese, G. (2021). Anxiety and climate change: a validation of the Climate Anxiety Scale in a German-speaking quota sample and an investigation of psychological correlates. Climatic Change, 168(3-4), 20. https://doi.org/10.1007/s10584-021-03234-6

Yang, Z. J., \& Kahlor, L. A. (2013). What, Me worry? The role of affect in information seeking and avoidance. Science Communication, 35(2), 189-212. https://doi.org/10.1177/1075547012441873

Zanocco, C., Boudet, H., Nilson, R., Satein, H., Whitley, H., \& Flora, J. (2018). Place, proximity, and perceived harm: extreme weather events and views about climate change. Climatic Change, 149(3-4), 349-365. https://doi.org/10.1007/s10584-018-2251-x 
Table 1. Descriptive statistics and reliability indices for negative climate-related emotions across countries

\begin{tabular}{lccccccc}
\hline Country & & & & $\begin{array}{c}\text { \% very or } \\
\text { extremely } \\
\text { "tense" }\end{array}$ & $\begin{array}{c}\text { \% very or } \\
\text { extremely } \\
\text { "anxious" }\end{array}$ & $\begin{array}{c}\text { \%very or } \\
\text { extremely } \\
\text { "worried" }\end{array}$ & $\begin{array}{c}\text { \% very or } \\
\text { extremely } \\
\text { "terrified" }\end{array}$ \\
\hline Australia & .90 & $3.22(.90)$ & 25.2 & 30.6 & 44.9 & 14.0 & 314 \\
Brazil & .91 & $3.76(.91)$ & 51.4 & 43.6 & 73.6 & 33.3 & 280 \\
Canada & .88 & $3.12(.78)$ & 18.4 & 21.7 & 40.1 & 14.9 & 309 \\
Chile & .83 & $3.31(.74)$ & 22.5 & 30.7 & 47.8 & 21.5 & 391 \\
China & .89 & $2.86(.81)$ & 19.1 & 22.1 & 33.7 & 15.0 & 267 \\
Finland & .92 & $3.26(.96)$ & 29.1 & 38.7 & 65.7 & 12.3 & 633 \\
Germany & .87 & $3.39(.84)$ & 32.1 & 27.6 & 63.0 & 36.2 & 246 \\
Italy & .89 & $3.41(.73)$ & 15.6 & 23.8 & 45.6 & 24.1 & 294 \\
India & .81 & $3.12(.76)$ & 25.3 & 22.3 & 37.6 & 21.4 & 228 \\
Indonesia & .84 & $3.32(.68)$ & 14.8 & 28.7 & 42.9 & 29.6 & 345 \\
Iran & .86 & $3.32(.84)$ & 34.7 & 28.5 & 42.1 & 26.6 & 322 \\
Japan & .73 & $3.05(.65)$ & 8.6 & 25.8 & 29.8 & 11.6 & 302 \\
Malaysia & .86 & $3.06(.71)$ & 14.8 & 15.2 & 33.3 & 18.9 & 264 \\
Netherlands & .88 & $3.20(.78)$ & 21.7 & 24.5 & 57.7 & 11.8 & 415 \\
Nigeria & .71 & $2.84(.73)$ & 22.0 & 26.8 & 27.2 & 25.1 & 584 \\
Norway & .87 & $3.09(.81)$ & 15.6 & 27.5 & 48.5 & 9.5 & 262 \\
Pakistan & .81 & $3.03(.80)$ & 26.5 & 21.6 & 37.6 & 26.9 & 245 \\
Palestine & .80 & $2.98(.78)$ & 21.6 & 28.2 & 26.0 & 19.7 & 360 \\
Philippines & .85 & $3.55(.73)$ & 28.4 & 37.1 & 63.0 & 44.5 & 1418 \\
Portugal & .87 & $3.43(.77)$ & 31.8 & 30.2 & 68.2 & 16.3 & 258 \\
Romania & .86 & $2.90(.84)$ & 13.9 & 14.4 & 30.6 & 17.7 & 395 \\
Russia & .75 & $2.71(.62)$ & 7.5 & 5.0 & 9.6 & 7.8 & 477 \\
Slovakia & .83 & $3.00(.77)$ & 11.2 & 27.1 & 32.6 & 14.7 & 258 \\
Spain & .86 & $3.66(.72)$ & 35.8 & 24.6 & 77.6 & 34.9 & 590 \\
Tanzania & .75 & $2.91(.72)$ & 19.0 & 19.0 & 28.6 & 21.4 & 248 \\
Uganda & .84 & $3.18(.87)$ & 27.0 & 31.4 & 45.6 & 35.1 & 653 \\
UAE & .87 & $3.33(.90)$ & 29.2 & 39.4 & 48.7 & 32.7 & 219 \\
UK & .88 & $3.26(.80)$ & 20.3 & 29.2 & 44.1 & 15.4 & 370 \\
Total & .86 & $3.22(.83)$ & 23.7 & 27.7 & 46.8 & 24.3 & 10,963 \\
\hline
\end{tabular}


Table 2. Descriptive statistics and reliability indices for pro-environmental behaviour, environmental activism, and mental wellbeing across countries.

\begin{tabular}{|c|c|c|c|c|c|c|}
\hline \multirow[b]{2}{*}{ Country } & \multicolumn{2}{|c|}{$\begin{array}{c}\text { Pro-environmental } \\
\text { behaviour }\end{array}$} & \multirow{2}{*}{$\begin{array}{c}\text { Attended } \\
\text { climate } \\
\text { protest } \\
\% \text { Yes }\end{array}$} & \multicolumn{2}{|c|}{$\begin{array}{l}\text { WHO- } 5 \text { wellbeing } \\
\text { index }\end{array}$} & \multirow[b]{2}{*}{$N$} \\
\hline & $\alpha$ & $\mathrm{M}(\mathrm{SD})$ & & $\alpha$ & $\mathrm{M}(\mathrm{SD})$ & \\
\hline Australia & .85 & $3.01(0.87)$ & 9.2 & .89 & $2.72(1.00)$ & 314 \\
\hline Brazil & .78 & $3.39(0.81)$ & 15.0 & .86 & $2.37(1.01)$ & 280 \\
\hline Canada & .81 & $2.99(0.80)$ & 5.8 & .86 & $2.59(0.99)$ & 309 \\
\hline Chile & .69 & $3.35(0.74)$ & 21.0 & .85 & $2.63(0.96)$ & 391 \\
\hline China & .79 & $3.54(0.72)$ & 0.4 & .87 & $2.59(0.86)$ & 267 \\
\hline Finland & .84 & $3.85(0.76)$ & 31.4 & .82 & $2.73(0.82)$ & 633 \\
\hline Germany & .79 & $3.48(0.77)$ & 28.5 & .71 & $2.67(0.79)$ & 246 \\
\hline Italy & .72 & $3.39(0.70)$ & 23.5 & .80 & $2.44(0.80)$ & 294 \\
\hline India & .72 & $3.57(0.68)$ & 19.7 & .81 & $3.17(0.98)$ & 228 \\
\hline Indonesia & .56 & $3.33(0.53)$ & 7.8 & .82 & $2.65(0.82)$ & 345 \\
\hline Iran & .69 & $3.37(0.68)$ & 5.3 & .89 & $2.59(1.17)$ & 322 \\
\hline Japan & .60 & $2.53(0.66)$ & 2.0 & .81 & $2.86(1.00)$ & 302 \\
\hline Malaysia & .75 & $3.22(0.66)$ & 5.3 & .87 & $2.90(0.90)$ & 264 \\
\hline Netherlands & .82 & $3.73(0.75)$ & 35.3 & .85 & $2.80(0.88)$ & 415 \\
\hline Nigeria & .72 & $3.07(0.72)$ & 10.3 & .77 & $3.19(0.93)$ & 584 \\
\hline Norway & .81 & $3.61(0.75)$ & 23.3 & .79 & $2.90(0.85)$ & 262 \\
\hline Pakistan & .61 & $3.14(0.64)$ & 18.4 & .75 & $2.59(1.02)$ & 245 \\
\hline Palestine & .74 & $3.06(0.71)$ & 6.8 & .75 & $2.94(0.99)$ & 360 \\
\hline Philippines & .70 & $3.67(0.63)$ & 5.1 & .85 & $2.65(0.93)$ & 1418 \\
\hline Portugal & .72 & $3.52(0.71)$ & 13.6 & .88 & $2.72(0.97)$ & 258 \\
\hline Romania & .76 & $2.94(0.78)$ & 3.0 & .80 & $2.85(0.86)$ & 395 \\
\hline Russia & .69 & $3.43(0.75)$ & 7.8 & .80 & $3.04(0.89)$ & 477 \\
\hline Slovakia & .71 & $3.23(0.74)$ & 2.7 & .78 & $2.47(0.79)$ & 258 \\
\hline Spain & .70 & $3.79(0.66)$ & 32.0 & .80 & $2.57(0.80)$ & 590 \\
\hline Tanzania & .69 & $3.55(0.69)$ & 25.4 & .76 & $3.42(0.95)$ & 248 \\
\hline Uganda & .73 & $3.55(0.73)$ & 11.6 & .74 & $2.99(0.95)$ & 653 \\
\hline UAE & .70 & $2.96(0.67)$ & 5.8 & .83 & $2.47(0.89)$ & 219 \\
\hline UK & .76 & $3.14(0.75)$ & 7.6 & .84 & $2.48(0.94)$ & 370 \\
\hline Total & .76 & $3.40(0.78)$ & 13.6 & .82 & $2.76(0.95)$ & 10,963 \\
\hline
\end{tabular}


Table 3. Predictors of negative climate-related emotions

\begin{tabular}{|c|c|c|c|}
\hline Predictors & Estimates & $95 \% \mathrm{Cl}(\mathrm{UL}, \mathrm{CL})$ & $p$ \\
\hline (Intercept) & 3.21 & $3.13,3.29$ & $<.001$ \\
\hline \multicolumn{4}{|l|}{ Media exposure } \\
\hline Rate & -.01 & $-.02, .01$ & .137 \\
\hline Attention & .14 & $.12, .16$ & $<.001$ \\
\hline thesing & -.01 & $-.02, .00$ & .067 \\
\hline Impact & .04 & $.03, .05$ & $<.001$ \\
\hline Solution & .01 & $-.01, .02$ & .268 \\
\hline \multicolumn{4}{|l|}{ Perceived norms } \\
\hline Descriptive & .02 & $-.01, .04$ & .268 \\
\hline Injunctive & .22 & $.20, .25$ & $<.001$ \\
\hline \multicolumn{4}{|l|}{ Experience } \\
\hline Flooding & -.01 & $-.05, .02$ & .488 \\
\hline Other & -.05 & $-.09,-.02$ & .001 \\
\hline \multicolumn{4}{|l|}{ Demographic covariates } \\
\hline Age & -.00 & $-.01,-.00$ & $<.001$ \\
\hline Gender (Female) & .23 & $.20, .26$ & $<.001$ \\
\hline \multicolumn{4}{|l|}{ Random effects } \\
\hline$\sigma^{2}$ & & .53 & \\
\hline To0 Country & & .05 & \\
\hline ICC & & .08 & \\
\hline$N_{\text {Country }}$ & & 28 & \\
\hline Observations & & 10,356 & \\
\hline Marginal $R^{2}$ /Conditional $R^{2}$ & & $.14 / .21$ & \\
\hline
\end{tabular}


Table 4. Predictors of pro-environmental actions and mental wellbeing

\begin{tabular}{|c|c|c|c|c|c|c|c|c|c|}
\hline \multirow[t]{2}{*}{ Predictors } & \multicolumn{3}{|c|}{ DV: Pro-environmental behaviour } & \multicolumn{3}{|c|}{ DV: Environmental activism } & \multicolumn{3}{|c|}{ DV: Mental wellbeing (WHO-5) } \\
\hline & Estimate & $95 \% \mathrm{Cl}(\mathrm{UL}, \mathrm{CL})$ & $p$ & Odds ratio & $95 \% \mathrm{Cl}(\mathrm{UL}, \mathrm{CL})$ & $p$ & Estimate & $95 \% \mathrm{Cl}(\mathrm{UL}, \mathrm{CL})$ & $p$ \\
\hline \multirow{2}{*}{$\begin{array}{l}\text { (Intercept) } \\
\text { Negative climate-related } \\
\text { emotions (NCE) }\end{array}$} & 3.36 & $3.27,3.45$ & $<.001$ & 0.10 & $.07, .15$ & $<.001$ & 2.74 & $2.66,2.82$ & $<.001$ \\
\hline & .12 & $.08, .16$ & $<.001$ & 1.14 & $.97,1.36$ & .116 & -.27 & $-.31,-.23$ & $<.001$ \\
\hline \multicolumn{10}{|l|}{ Media exposure } \\
\hline Rate & .01 & $-.00, .02$ & .078 & 1.14 & $1.08,1.20$ & $<.001$ & .04 & $.02, .05$ & $<.001$ \\
\hline Attention & .21 & $.19, .23$ & $<.001$ & 1.76 & $1.59,1.94$ & $<.001$ & .08 & $.05, .10$ & $<.001$ \\
\hline Cause & .02 & $.01, .03$ & $<.001$ & 1.07 & $1.03,1.12$ & .003 & .01 & $-.01, .02$ & .332 \\
\hline Impact & .00 & $-.01, .01$ & .455 & 1.03 & $.97,1.07$ & .533 & -.00 & $-.02, .01$ & .652 \\
\hline Solution & .01 & $-.01, .02$ & .117 & 1.05 & $1.00,1.10$ & .046 & .01 & $.00, .03$ & .034 \\
\hline \multicolumn{10}{|l|}{ Perceived norms } \\
\hline Descriptive & .08 & $.05, .10$ & $<.001$ & 1.02 & $.90,1.15$ & .750 & .00 & $-.03, .03$ & .917 \\
\hline Injunctive & .03 & $.01, .05$ & .014 & 1.06 & $.94,1.19$ & .343 & .07 & $.04, .10$ & $<.001$ \\
\hline \multicolumn{10}{|l|}{$\begin{array}{l}\text { Extreme weather } \\
\text { experience }\end{array}$} \\
\hline Flooding & .01 & $-.03, .04$ & .708 & .98 & $.84,1.14$ & .776 & -.02 & $-.06, .02$ & .398 \\
\hline Other & -.03 & $-.05, .00$ & .086 & 1.11 & $.96,1.28$ & .160 & .04 & $.00, .08$ & .034 \\
\hline \multicolumn{10}{|l|}{ Demographic covariates } \\
\hline Age & .00 & $-.00, .00$ & .249 & 1.00 & $1.00,1.01$ & .331 & .01 & $.00, .01$ & $<.001$ \\
\hline Gender (Female) & .05 & $.02, .08$ & .001 & 1.02 & $.88,1.17$ & .834 & -.09 & $-.13,-.05$ & $<.001$ \\
\hline \multicolumn{10}{|l|}{ Random effects } \\
\hline$\sigma^{2}$ & & .44 & & & 3.29 & & & .77 & \\
\hline T00 Country & & .06 & & & .76 & & & .04 & \\
\hline $\mathrm{T}_{11}$ Country.NCE & & .01 & & & .13 & & & .01 & \\
\hline ICC & & .13 & & & .20 & & & .06 & \\
\hline$\rho_{01}$ Country & & .20 & & & .71 & & & .50 & \\
\hline$N$ Country & & 28 & & & 28 & & & 28 & \\
\hline Observations & & 10,354 & & & 10,336 & & & 10,354 & \\
\hline $\begin{array}{l}\text { Marginal } R^{2} / \text { Conditional } \\
R^{2}\end{array}$ & & $.15 / .26$ & & & $.13 / .30$ & & & $.07 / .13$ & \\
\hline
\end{tabular}

Estimates are unstandardised regression coefficients. 


\begin{tabular}{|c|c|c|c|c|c|c|c|c|c|c|}
\hline \multirow[b]{2}{*}{ Country } & \multirow[b]{2}{*}{$N$} & \multirow{2}{*}{$\begin{array}{c}\text { Age } \\
\text { (in years) } \\
\text { M(SD) }\end{array}$} & \multicolumn{2}{|c|}{ Gender (\%)* } & \multicolumn{6}{|c|}{ Discipline (\%)* } \\
\hline & & & Female & Male & $\begin{array}{l}\text { Agricultural } \\
\text { Sciences }\end{array}$ & $\begin{array}{l}\text { Engineering } \\
\text { and } \\
\text { Technology }\end{array}$ & Humanities & $\begin{array}{l}\text { Medical } \\
\text { and } \\
\text { Health } \\
\text { Sciences }\end{array}$ & $\begin{array}{l}\text { Natural } \\
\text { Sciences }\end{array}$ & $\begin{array}{c}\text { Social } \\
\text { Sciences }\end{array}$ \\
\hline Australia & 314 & $35.6(11.0)$ & 73.2 & 25.8 & 0.8 & 0.8 & 3.0 & 12.2 & 2.1 & 73.8 \\
\hline Brazil & 280 & $30.6(12.8)$ & 72.9 & 27.1 & 1.8 & 8.2 & 10.4 & 10.7 & 5.4 & 51.1 \\
\hline Canada & 309 & $18.3(1.1)$ & 66.3 & 32.4 & - & - & 0.3 & - & 0.3 & 97.1 \\
\hline Chile & 391 & $23.9(9.3)$ & 56.0 & 38.6 & 0.5 & 16.6 & 9.0 & 12.3 & 4.3 & 32.7 \\
\hline China & 267 & $21.3(2.9)$ & 69.7 & 28.1 & 0.4 & 0.7 & 1.9 & - & - & 97.0 \\
\hline Finland & 633 & $26.9(7.1)$ & 74.2 & 20.1 & 10.9 & 0.8 & 31.0 & 1.4 & 25.9 & 28.4 \\
\hline Germany & 246 & $23.5(5.6)$ & 68.7 & 30.5 & - & 11.0 & 6.9 & - & 2.8 & 62.2 \\
\hline Italy & 294 & $21.5(2.5)$ & 75.5 & 21.8 & - & - & - & - & - & 100 \\
\hline India & 229 & $24.5(5.8)$ & 42.4 & 55.0 & 0.9 & 19.7 & 3.5 & 1.7 & 1.7 & 11.4 \\
\hline Indonesia & 345 & $19.4(1.6)$ & 78.0 & 19.1 & - & - & 1.7 & 0.3 & - & 93.0 \\
\hline Iran & 323 & $24.6(4.9)$ & 60.7 & 36.8 & 0.9 & 16.1 & 44.9 & 3.7 & 20.1 & 8.0 \\
\hline Japan & 302 & $19.9(1.1)$ & 22.8 & 71.2 & 0.3 & 1.3 & 7.3 & 0.7 & 2.3 & 87.7 \\
\hline Malaysia & 264 & $20.4(1.7)$ & 67.8 & 29.9 & - & 1.1 & 0.8 & 1.1 & 1.1 & 93.9 \\
\hline Netherlands & 416 & $24.1(6.0)$ & 64.4 & 33.4 & 0.5 & 3.8 & 7.0 & 1.2 & 38.9 & 32.2 \\
\hline Nigeria & 583 & $25.1(8.0)$ & 50.4 & 45.5 & 5.8 & 14.2 & 5.5 & 7.2 & 3.1 & 60.5 \\
\hline Norway & 262 & $23.9(4.7)$ & 70.6 & 26.7 & 0.4 & 3.4 & 7.3 & 9.9 & 5.0 & 70.2 \\
\hline Pakistan & 245 & $20.6(2.4)$ & 57.1 & 40.4 & 0.8 & 0.8 & 20.0 & - & 2.4 & 45.3 \\
\hline Palestine & 365 & $20.4(3.0)$ & 63.3 & 24.9 & 0.5 & 4.4 & 12.9 & 1.4 & 1.9 & 55.9 \\
\hline Philippines & 1418 & 19.4(3.1) & 64.5 & 29.3 & 0.2 & 3.7 & 5.1 & 3.7 & 0.8 & 59.1 \\
\hline Portugal & 258 & $32.2(13.9)$ & 73.6 & 24.8 & 1.6 & 10.5 & 3.9 & 5.8 & 7.0 & 61.2 \\
\hline Romania & 395 & $21.3(1.6)$ & 66.6 & 33.4 & 3.3 & 14.7 & 11.6 & 8.9 & 7.3 & 54.2 \\
\hline Russia & 477 & $25.1(8.4)$ & 78.2 & 18.4 & 1.5 & 8.6 & 17.8 & 4.0 & 4.8 & 48.8 \\
\hline Slovakia & 258 & $21.0(1.4)$ & 79.1 & 20.2 & - & - & - & 43.0 & 12.8 & 36.4 \\
\hline Spain & 590 & $23.7(6.2)$ & 80.7 & 19.2 & 2.0 & 4.6 & 7.1 & 14.9 & 7.3 & 45.6 \\
\hline Tanzania & 248 & $24.2(3.6)$ & 23.8 & 71.0 & 16.1 & 64.1 & 1.2 & 0.4 & 0.4 & 2.8 \\
\hline Uganda & 653 & $26.0(5.9)$ & 17.8 & 80.6 & 0.2 & 97.5 & - & 0.2 & - & - \\
\hline UAE & 226 & $21.1(3.0)$ & 72.6 & 6.2 & 0.4 & 4.0 & 6.2 & 7.1 & 9.3 & 39.4 \\
\hline United Kingdom & 370 & $20.2(4.0)$ & 89.5 & 10.3 & - & - & - & 4.3 & 0.3 & 94.9 \\
\hline Total & 10143 & $23.4(7.3)$ & 63.4 & 33.6 & 4.9 & 12.8 & 8.4 & 5.5 & 6.3 & 51.2 \\
\hline
\end{tabular}

*Percentages for gender and discipline distributions may not add up to $100 \%$ due to participants indicating 'other' or 'prefer not to say' not included in table. 
Supplementary Table 2. Country-wise descriptive and reliability statistics for media exposure rate, attention, and content.

\begin{tabular}{|c|c|c|c|c|c|c|}
\hline \multirow[b]{3}{*}{ Country } & \multirow{2}{*}{\multicolumn{2}{|c|}{$\begin{array}{c}\text { Media Exposure } \\
\text { (Rate) }\end{array}$}} & \multirow{3}{*}{$\begin{array}{c}\text { Attention } \\
\mathrm{M}(\mathrm{SD})\end{array}$} & \multicolumn{3}{|c|}{ Media content } \\
\hline & & & & Cause & Impact & Solutions \\
\hline & $\alpha$ & $M(S D)$ & & $\mathrm{M}(\mathrm{SD})$ & $\mathrm{M}(\mathrm{SD})$ & $\mathrm{M}(\mathrm{SD})$ \\
\hline Australia & .76 & $3.36(1.32)$ & $2.94(0.79)$ & $4.07(2.09)$ & $4.91(2.08)$ & $4.37(2.03)$ \\
\hline Brazil & .87 & $3.93(1.76)$ & $3.39(0.77)$ & $3.98(2.26)$ & $4.32(2.28)$ & $4.28(2.27)$ \\
\hline Canada & .86 & $3.45(1.52)$ & $2.69(0.72)$ & $3.79(1.95)$ & $4.07(1.83)$ & $3.83(1.76)$ \\
\hline Chile & .82 & $4.02(1.70)$ & $3.26(0.74)$ & $4.62(2.23)$ & $5.18(2.09)$ & $4.80(2.11)$ \\
\hline China & .84 & 7.58(1.07) & $2.23(0.76)$ & 7.34(1.32) & $6.99(1.33)$ & $7.49(1.11)$ \\
\hline Finland & .71 & $3.33(1.14)$ & $3.50(0.65)$ & $4.26(1.86)$ & $4.52(1.73)$ & $4.63(1.75)$ \\
\hline Germany & .73 & $3.43(1.30)$ & $2.69(0.73)$ & $3.77(1.70)$ & $4.58(1.76)$ & $4.43(1.83)$ \\
\hline Italy & .83 & $4.02(1.51)$ & $3.12(0.62)$ & $4.34(1.82)$ & $5.16(1.68)$ & $4.60(1.84)$ \\
\hline India & .82 & $4.10(1.61)$ & $3.03(0.68)$ & $4.16(2.24)$ & $4.55(2.14)$ & $4.28(2.12)$ \\
\hline Indonesia & .77 & $2.79(1.22)$ & $2.84(0.62)$ & $3.06(1.85)$ & $3.74(1.85)$ & $3.48(1.94)$ \\
\hline Iran & .87 & $2.68(1.48)$ & $2.71(0.82)$ & $2.83(2.02)$ & $3.05(1.98)$ & $2.80(2.03)$ \\
\hline Japan & .82 & $2.24(1.11)$ & $3.14(0.74)$ & $2.27(1.39)$ & $2.20(1.31)$ & $1.99(1.31)$ \\
\hline Malaysia & .87 & $3.47(1.60)$ & $2.74(0.65)$ & $3.57(2.05)$ & $3.89(2.04)$ & $3.59(2.01)$ \\
\hline Netherlands & .67 & $3.64(1.19)$ & $3.43(0.65)$ & $4.68(1.92)$ & $4.92(1.84)$ & $4.83(1.74)$ \\
\hline Nigeria & .86 & $4.09(1.80)$ & $2.81(0.94)$ & $4.31(2.50)$ & $4.20(2.31)$ & $4.15(2.24)$ \\
\hline Norway & .76 & $3.33(1.17)$ & $3.31(0.63)$ & $3.70(1.69)$ & $4.23(1.64)$ & $4.21(1.61)$ \\
\hline Pakistan & .87 & $3.81(1.79)$ & $2.67(0.88)$ & $3.90(2.29)$ & $4.28(2.31)$ & $3.80(2.23)$ \\
\hline Palestine & .83 & $3.35(1.59)$ & $2.37(0.82)$ & $3.25(2.24)$ & $3.33(2.11)$ & $3.20(2.09)$ \\
\hline Philippines & .85 & $4.93(1.70)$ & $3.09(0.65)$ & $4.93(2.29)$ & $5.57(2.17)$ & $5.24(2.17)$ \\
\hline Portugal & .75 & $3.72(1.35)$ & $1.57(0.56)$ & $4.52(1.99)$ & $4.98(1.90)$ & $4.49(1.90)$ \\
\hline Romania & .82 & $3.37(1.48)$ & $2.88(0.80)$ & $3.52(2.09)$ & $4.39(2.07)$ & $3.62(2.10)$ \\
\hline Russia & .83 & $2.70(1.31)$ & $2.50(0.87)$ & $3.04(1.84)$ & $3.25(1.79)$ & $2.85(1.75)$ \\
\hline Slovakia & .81 & $3.05(1.24)$ & $2.44(0.84)$ & $2.75(1.68)$ & $3.78(1.89)$ & $3.10(1.76)$ \\
\hline Spain & .71 & $3.57(1.33)$ & $3.60(0.58)$ & $4.24(2.00)$ & $4.96(1.94)$ & $4.51(1.96)$ \\
\hline Tanzania & .88 & $4.53(1.84)$ & $3.28(0.80)$ & $5.00(2.26)$ & $4.97(2.31)$ & $4.95(2.24)$ \\
\hline Uganda & .89 & $3.85(1.78)$ & $3.23(0.73)$ & $4.15(2.23)$ & $4.19(2.18)$ & $4.01(2.17)$ \\
\hline UAE & .73 & $3.22(1.32)$ & $2.07(0.91)$ & $4.74(2.79)$ & $4.70(2.60)$ & $4.29(2.74)$ \\
\hline United Kingdom & .81 & $3.39(1.42)$ & $2.74(0.67)$ & $3.36(1.88)$ & $4.18(1.83)$ & $3.87(1.96)$ \\
\hline Total & .85 & $3.77(1.74)$ & $2.95(0.85)$ & $4.09(2.24)$ & $4.49(2.18)$ & $4.23(2.20)$ \\
\hline
\end{tabular}


Supplementary Table 3. Country-wise descriptive and reliability statistics for perceived social norms and extreme weather experience

\begin{tabular}{lcccccc}
\hline & \multicolumn{3}{c}{ Social Norms } & \multicolumn{2}{c}{$\begin{array}{c}\text { Extreme Weather } \\
\text { Experience }\end{array}$} \\
\cline { 2 - 7 } Country & \multicolumn{2}{c}{ Descriptive } & \multicolumn{2}{c}{ Injunctive } & Flooding & Other \\
\cline { 2 - 7 } Australia & .8 & M(SD) & $\alpha$ & M(SD) & \%Yes & $\%$ Yes \\
Brazil & .82 & $3.61(0.88)$ & .82 & $3.43(0.90)$ & 81.2 & 57.6 \\
Canada & .82 & $3.52(0.79)$ & .79 & $3.13(0.87)$ & 61.4 & 48.6 \\
Chile & .82 & $3.59(0.87)$ & .84 & $3.36(0.86)$ & 91.6 & 79.9 \\
China & .80 & $3.56(0.68)$ & .66 & $3.44(0.76)$ & 45.8 & 66.2 \\
Finland & .80 & $3.33(0.75)$ & .86 & $2.86(0.69)$ & 95.5 & 48.7 \\
Germany & .80 & $3.86(0.73)$ & .77 & $3.69(0.80)$ & 35.2 & 78.5 \\
Italy & .63 & $3.80(0.68)$ & .71 & $3.44(0.67)$ & 88.6 & 71.1 \\
India & .67 & $3.55(0.61)$ & .61 & $3.24(0.66)$ & 77.9 & 68.0 \\
Indonesia & .84 & $3.59(0.88)$ & .81 & $3.39(0.91)$ & 38.0 & 48.0 \\
Iran & .76 & $3.57(0.67)$ & .79 & $3.25(0.64)$ & 78.0 & 77.4 \\
Japan & .79 & $3.03(0.91)$ & .78 & $2.98(0.93)$ & 41.5 & 49.2 \\
Malaysia & .77 & $3.21(0.82)$ & .84 & $2.70(0.75)$ & 93.0 & 86.1 \\
Netherlands & .84 & $3.10(0.81)$ & .80 & $2.93(0.83)$ & 79.9 & 76.1 \\
Nigeria & .72 & $3.75(0.75)$ & .74 & $3.48(0.76)$ & 92.1 & 74.3 \\
Norway & .77 & $3.17(0.84)$ & .77 & $2.98(0.84)$ & 68.7 & 71.1 \\
Pakistan & .76 & $3.81(0.74)$ & .79 & $3.52(0.77)$ & 86.6 & 80.9 \\
Palestine & .72 & $3.46(0.69)$ & .75 & $3.30(0.73)$ & 83.3 & 78.8 \\
Philippines & .74 & $2.87(0.76)$ & .78 & $2.78(0.72)$ & 27.7 & 68.5 \\
Portugal & .75 & $3.92(0.77)$ & .81 & $3.72(0.76)$ & 59.0 & 55.3 \\
Romania & .76 & $3.63(0.57)$ & .48 & $3.32(0.70)$ & 43.0 & 72.1 \\
Russia & .69 & $3.34(0.75)$ & .70 & $2.81(0.70)$ & 82.5 & 60.0 \\
Slovakia & .82 & $3.18(0.73)$ & .78 & $3.06(0.79)$ & 48.8 & 70.6 \\
Spain & .76 & $3.20(0.68)$ & .72 & $2.91(0.71)$ & 92.6 & 60.5 \\
Tanzania & .76 & $3.55(0.65)$ & .63 & $3.28(0.74)$ & 88.8 & 65.3 \\
Uganda & .76 & $3.84(0.84)$ & .77 & $3.75(0.87)$ & 79.0 & 77.0 \\
UAE & .81 & $3.80(0.94)$ & .81 & $3.58(0.99)$ & 66.2 & 72.1 \\
United Kingdom & .80 & $3.23(0.86)$ & .79 & $3.04(0.85)$ & 70.4 & 52.7 \\
Total & .82 & $3.46(0.91)$ & .80 & $3.26(0.94)$ & 71.9 & 72.2 \\
& .80 & $3.54(0.83)$ & .80 & $3.30(0.86)$ & 67.0 & 66.9 \\
\hline
\end{tabular}

